This item was submitted to Loughborough's Research Repository by the author.

Items in Figshare are protected by copyright, with all rights reserved, unless otherwise indicated.

\title{
Analysis of flame structure using detailed chemistry and applicability of flamelet/progress variable model in the laminar counter-flow diffusion flames of pulverized coals
}

\section{PLEASE CITE THE PUBLISHED VERSION}

https://doi.org/10.1016/j.apt.2019.12.019

\section{PUBLISHER}

Elsevier and The Society of Powder Technology Japan

\section{VERSION}

AM (Accepted Manuscript)

\section{PUBLISHER STATEMENT}

This paper was accepted for publication in the journal Advanced Powder Technology and the definitive published version is available at https://doi.org/10.1016/j.apt.2019.12.019

\section{LICENCE}

CC BY-NC-ND 4.0

\section{REPOSITORY RECORD}

Akaotsu, Shota, Yohsuke Matsushita, Hideyuki Aoki, and Weeratunge Malalasekera. 2020. "Analysis of Flame Structure Using Detailed Chemistry and Applicability of Flamelet/progress Variable Model in the Laminar Counter-flow Diffusion Flames of Pulverized Coals". Loughborough University.

https://hdl.handle.net/2134/13055732.v1. 


\title{
Analysis of flame structure using detailed chemistry and applicability of flamelet/progress variable model in the laminar counter-flow diffusion flames of pulverized coals
}

\author{
Shota Akaotsu ${ }^{\mathrm{a}, *}$, Yohsuke Matsushita ${ }^{\mathrm{a}}$, Hideyuki Aoki ${ }^{\mathrm{a}}$, Weeratunge \\ Malalasekera ${ }^{b}$ \\ ${ }^{a}$ Department of Chemical Engineering, Graduate School of Engineering, Tohoku University, \\ 6-6-07 Aoba, Aramaki, Aoba-ku, Sendai, Miyagi, 980-8579, Japan \\ ${ }^{b}$ School of Mechanical, Electrical and Manufacturing Engineering, Loughborough University, \\ Loughborough LE11 3TU, UK
}

\begin{abstract}
Pulverized coal is still found in many practical devices even though it is recognized as "dirty fuel" because of its $\mathrm{CO}_{2}$ and pollutant emissions. To overcome this problem, advanced coal utilization technologies have been developed using numerical simulations. In this study, the structures of the laminar counter-flow diffusion flames of pulverized coals were investigated by performing simulations based on detailed chemistry. The high-temperature region became narrower as the coal/air ratio increased, because of the departure from the stoichiometric mixture and local quenching by the heat transfer between the gas and solid phases. Further, the applicability of the flamelet/progress-variable (FPV) model was investigated through a priori and a posterior $i$ tests. The a priori test confirmed that the FPV model is capable of reproducing the numerical solutions obtained using the detailed chemistry, including the mass fractions of minor species. In the a posteriori test, there was a slight difference between the FPV model and detailed chemistry results due to overestimation of the progress of the chemical reactions. Given the sufficiently high accuracy of the FPV model in various numerical conditions, it can be concluded that the extended FPV model has potential for use in turbulent coal combustion simulations.
\end{abstract}

\footnotetext{
* Corresponding author

Email address: akaotsu@dc.tohoku.ac.jp (Shota Akaotsu)
}

Preprint submitted to Journal of ${ }^{A} T_{E} X$ Templates

August 4, 2019 
Keywords: numerical simulation, pulverized coal combustion, flamelet/progress variable model, detailed chemistry

\section{Introduction}

Although coal utilization has tended to decrease in certain fields due to the recognition of coal as "dirty fuel," coal-fired thermal plants are still the main systems for electricity generation in some developing countries. As indicators of the 5 suitability of fossil fuels, energy security, economy, environmental conservation, and safety are comprehensively evaluated in many countries. By evaluating the wide distribution, large reserves, and reasonable cost of coal, the Japanese government is developing a future energy plan in which coal works as the baseload energy source and regulated power supply for renewable energy sources such as solar and wind power. In fact, several developed countries are replacing old, inefficient plants with new, more efficient plants to minimize the emissions of pollutants, including $\mathrm{CO}_{2}$. With respect to the conventional coal combustion technologies, a system involving the co-firing of woody biomass with coals has been developed and implemented in some power plants. Ammonia combustion has also been promoted by the Japanese government, and a system including the co-firing of ammonia with coals has been investigated by several research groups. An integrated gasification combined cycle and chemical looping combustion system also expanded the coal utilization field and has the potential to support the stable supply of electricity to society.

Pulverized coal combustion is one of the most important processes in this system, where the chemical energy of coal is converted into thermal energy. Thus, detailed investigation of the coal combustion process will accelerate the development of the above technologies. The coal combustion process in industrial facilities includes turbulence, heat transfer through radiation, and chemical reactions in the gas phase, as well as the chemical reactions of coals. Various interactions such as turbulence-chemistry and solid-gas interactions make it difficult to understand and predict the combustion behavior in furnaces. Since 
the above interactions progress in very small spaces and on fast time scales, experimental data are limited, and more detailed data are required to understand the coal combustion process. To clarify the coal combustion process, numerical simulations are utilized and have enabled considerable achievements in recent decades. Although methods of modeling the gas-solid and particleturbulence interactions in particle motion have been established, the modeling of turbulence-chemistry interactions is an outstanding problem. The eddy break up (EBU) model [ $[\mathrm{I}]$ and eddy dissipation model or eddy dissipation concept [2, 3] are well-known in the method involving Reynolds-averaged Navier-Stokes equations. Assuming infinitely fast chemistry, the reaction rate of the fuel gas is evaluated based on the mixing rate of fuel and the oxidant eddies in these models. A scale similarity filtered reaction rate model [4] was developed as the 40 turbulent combustion model in large eddy simulations (LESs). The concept of scale similarity, which is often used to model the eddy viscosity, is applied to calculate the unresolved component in the reaction rate, and the reaction rate in turbulence is evaluated as the overall reaction rate with the resolved and unresolved parts combined. In the above methods, a chemical reaction is considered in a global reaction that does not include the intermediate species and actual chemical kinetics. Accordingly, some researchers have noted that the above combustion models overestimate the reaction rate [5-9]. To overcome its limitations, flamelet-based tabulated chemistry has been expanded to pulverized coal combustion by several researchers [10, II]]. Vascellari et al. [10] numerically investigated the coal ignition process in the experiments using laminar entrained-flow reactors that were conducted by Molina and Shaddix [II2]. Firstly, they performed a computational fluid dynamics (CFD) simulation using the Euler-Lagrange approach to obtain the transient gas velocity, gas temperature, particle temperature, and devolatilization rate. The obtained transient data were used as the boundary conditions in the subsequent detailed simulation around a single coal particle, called a resolved particle simulation. In this simulation, the additional balance equation of the mixture fraction $Z$ was solved under the boundary conditions with $Z=1$ 
at the particle surface and $Z=0$ at the coflow inlet. In addition, unsteady flamelet equations were solved using the scalar dissipation rate obtained from the resolved particle simulations, and the numerical solutions from the flamelet model were compared with those acquired using the detailed chemistry. Although the flamelet calculations could not capture the subsequent ignition from upstream to downstream around the particle, they reproduced the temperature and species profiles before and after ignition. Based on these results, the authors indicated the applicability of the flamelet model for pulverized coal combustion. Notably, char combustion was not considered because the focus was on the ignition process during devolatilization. Thereafter, Watanabe and Yamamoto [II] proposed a method of flamelet modeling for the overall coal combustion 70 process, including char combustion. Based on this method, the authors verified the applicability of the flamelet/progress-variable (FPV) model to the coal combustion process by comparing the numerical solutions with those obtained using detailed chemistry. The temperature and species distribution calculated using the FPV model agreed with those acquired using the detailed chemistry, although the FPV model showed earlier ignition. The authors concluded that the FPV model lacks information in the unsteady state, which is important during ignition, and that the accuracy may be improved by unsteady flamelet calculation or the utilization of different progress variables. Wen et al. [1]3] also evaluated the accuracy of the FPV model in the laminar counter-flow diffusion flames of pulverized coals and showed that the temperature and species distributions predicted using the detailed chemistry were approximately reproduced by the FPV model.

Recently, LESs of pulverized coal flames have been performed using the flamelet approach because the sufficiently high accuracy of the FPV model has been confirmed in the detailed verification of the laminar flow. Rieth et al. [14, 15] implemented the FPV model in LES of a realistic coal furnace, called an international flame research foundation (IFRF) furnace, and predicted the coal combustion behavior. It should be mentioned that these authors introduced the concept of char off-gas and used a mixture fraction of char different from 

complicated process of char combustion implementation in the FPV model more concise. Comparison of the numerical solutions with the experimental data indicated that the FPV model extended to coal combustion worked well even in turbulence flow fields. Wen et al. [13, 16] also conducted LESs of an IFRF to the EBU model. Consequently, flamelet-based tabulated chemistry has great potential in the coal combustion field as well as in gas and spray combustion, and knowledge of the detailed characteristics and limitations of the FPV model will be useful for future CFD simulation of pulverized coal combustion. modeling of coal combustion and to verify the accuracy of the FPV model in the laminar counter-flow diffusion flame. Firstly, the look-up tables were constructed according to the two mixture fraction approach described by Rieth et al. [14, 15] in section [2. The additional dimension for heat exchange between the gas and solid phases was prepared by changing the boundary temperature, and four-dimensional look-up tables were constructed prior to performing the CFD simulation. Section $\mathbf{B}$ describes the numerical methods such as the geometry of computational domain and discretization schemes. The changes in the flame structure were observed under various coal/air ratios using the detailed chemistry in section $4 . \sqrt{4.3}$. Then, the flame index (FI), which is one of the most popular indicators of the local combustion mode, was introduced and the reaction process of a coal flame was investigated in detail. To verify the FPV model, a priori and posteriori tests were conducted to identify the cause of the discrepancy from the detailed chemistry results based on the accuracy of the look-up tables in section 4.4. The availability of the FPV model for pulverized coal combustion was assessed by comparing the FPV model solutions with the detailed chemistry results under various numerical conditions. 


\section{Coal combustion modeling using FPV model}

\subsection{Extension of the FPV model to coal combustions}

In CFD with the FPV model, look-up tables, which are constructed by onedimensional calculation of the counter-flow diffusion flame, are utilized to obtain thermochemical quantities such as fluid density and viscosity. In this study, one-dimensional calculations were performed using the FlameMaster software library [17]. Then, the steady-state flamelet equations were solved with a unity Lewis number assumption for all chemical species. Generally, the composition and temperature of both the fuel and oxidizer streams in the target domain are given for the boundary conditions, and each thermochemical quantity is aligned with the multi-dimensional coordinates: mixture fraction, progress variable, and other representative variables. As all thermochemical quantities are retrieved through only the representative variables, CFD simulation which includes the information of detailed chemistry can be conducted with reasonable computational cost by solving only the transport equations of the mixture fraction and progress variable.

Watanabe and Yamamoto [II] extended the FPV model to pulverized coal combustion, including the char combustion process based on the two mixture fraction approach. The two mixture fraction approach [18, [1.9] was employed to describe the two types of fuel gas generated by devolatilization and char combustion, whereas the heat transfer between the solid and gas phases was represented by adding enthalpy to the representative variables. Although there is a slight difference between the mixture fraction definitions and heat loss modeling, nearly all previous studies (e.g., [1.3, [1.5]) have been based on this concept and have yielded high accuracies in the various domains. In this study, we followed the approach of Rieth et al. [14], as described in detail in the following paragraphs.

145 Two types of mixture fraction were defined as follows:

$$
Z_{\mathrm{vol}}=\frac{\dot{m}_{\mathrm{devol}}}{\dot{m}_{\mathrm{devol}}+\dot{m}_{\mathrm{char}}+\dot{m}_{\mathrm{ox}}},
$$




$$
Z_{\text {char }}=\frac{\dot{m}_{\text {char }}^{*}}{\dot{m}_{\text {devol }}+\dot{m}_{\text {char }}+\dot{m}_{\text {ox }}},
$$

where $\dot{m}_{\text {char }}, \dot{m}_{\text {devol }}$ and $\dot{m}_{\text {ox }}$ are the mass fluxes originating respectively from char, volatile matter, and oxidant gas, which was defined as air in this study, and $\dot{m}_{\text {char }}^{*}$ is the mass flux of $\mathrm{CO} / \mathrm{N}_{2}$ gas called "char off-gas" and is related to

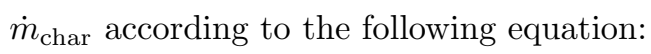

$$
\dot{m}_{\mathrm{char}}^{*}=\dot{m}_{\mathrm{char}}\left(1+S_{\mathrm{O}_{2}}+S_{\mathrm{N}_{2}}\right)
$$

where $S_{\mathrm{O}_{2}}(=16 / 12 \approx 1.33)$ and $S_{\mathrm{N}_{2}}(=0.5 \gamma \times 28 / 12 \approx 4.388)$ are the $\mathrm{O}_{2}$ and $\mathrm{N}_{2}$ consumptions, respectively, per unit mass of fuel in the char combustion, and $\gamma$ is the volume ratio of $\mathrm{N}_{2}$ to $\mathrm{O}_{2}$ in the oxidant gas, which is $0.79 / 0.21 \approx 3.76 \mathrm{in}$ air. All of the thermochemical quantities were tabulated along with the sum of the two mixture fractions, $Z$, and and the ratio of the char off-gas to the overall fuel gas, $Z_{2}$ as

$$
\begin{aligned}
Z & =Z_{\mathrm{vol}}+Z_{\mathrm{char}}, \\
Z_{2} & =\frac{Z_{\text {char }}}{Z_{\text {char }}+Z_{\mathrm{vol}}}\left(=\frac{\dot{m}_{\mathrm{char}}^{*}}{\dot{m}_{\mathrm{devol}}+\dot{m}_{\mathrm{char}}^{*}}\right) .
\end{aligned}
$$

$Z$ and $Z_{2}$ range from zero to unity, which is suitable for the tabulation of the data from the one-dimensional calculations. Using $Z_{2}$, the composition of the overall fuel can be expressed as

$$
\begin{aligned}
Y_{\text {Fuel }, \mathrm{k}} & =\left(\frac{\dot{m}_{\mathrm{devol}}}{\dot{m}_{\mathrm{devol}}+\dot{m}_{\mathrm{char}}^{*}}\right) Y_{\mathrm{vol}, \mathrm{k}}+\left(\frac{\dot{m}_{\mathrm{char}}^{*}}{\dot{m}_{\mathrm{devol}}+\dot{m}_{\mathrm{char}}^{*}}\right) Y_{\text {char }, \mathrm{k}} \\
& =\left(1-Z_{2}\right) Y_{\mathrm{vol}, \mathrm{k}}+Z_{2} Y_{\text {char }, \mathrm{k}}
\end{aligned}
$$

where $Y_{\mathrm{vol}, \mathrm{k}}$ and $Y_{\mathrm{char}, \mathrm{k}}$ are the mass fractions of chemical species $k$ in the volatile and char off-gas, respectively. Note that these values were determined

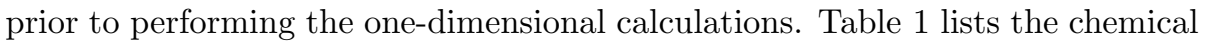
compositions of the fuel gases. Specifying the chemical species that constitute the volatile gas, $Y_{\mathrm{vol}, \mathrm{k}}$ is determined based on proximate and ultimate analyses of the coal, as described in [116]. $Y_{\text {char,k }}$ is given by the following char combustion formula: 


$$
\mathrm{C}+0.5\left(\mathrm{O}_{2}+\gamma \mathrm{N}_{2}\right) \rightarrow \mathrm{CO}+0.5 \gamma \mathrm{N}_{2}
$$

The char off-gas consists of $\mathrm{CO}$ and $\mathrm{N}_{2}$, and the volume and mass ratios are $1.0: 0.5 \gamma$ and $28: 14 \gamma \approx 0.347: 0.653$, respectively. Table $\square$ specifies the software library and chemical reaction mechanism employed in the one-dimensional calculations. Using FlameMaster [17], the flamelet equations were solved in the one-dimensional counter-flow diffusion flame in the mixture fraction space. Given the computational cost, DRM 22 [20], which consists of 22 chemical species and 103 chemical reactions, was used as the reaction mechanism according to the previous pulverized coal combustion simulation [III, 2I]. Wen et al. [2I] investigated the effects of the chemical reaction mechanism used to 175 simulate pulverized coal combustion and showed the minor differences between DRM 22 and GRI-mech 3.0 [ㄹㄹ , which is the most popular reaction mechanism for the detailed chemical analysis of light hydrocarbons. To demonstrate the accuracy of DRM 22, the numerical results are compared with those obtained using GRI-mech 3.0 in the appendix.

Table 1. Fuel compositions of volatile and char off-gas on a mass basis.

\begin{tabular}{lcc}
\hline & $Y_{\text {vol, } \mathrm{k}}$ & $Y_{\text {char }, \mathrm{k}}$ \\
\hline $\mathrm{CO}$ & 0.34 & 0.347 \\
$\mathrm{CH}_{4}$ & 0.55 & 0.0 \\
$\mathrm{C}_{2} \mathrm{H}_{2}$ & 0.11 & 0.0 \\
$\mathrm{~N}_{2}$ & 0.0 & 0.653 \\
\hline
\end{tabular}


Table 2. Calculation methods employed to construct the look-up tables.

\begin{tabular}{|c|c|c|}
\hline Software library & & FlameMaster [I] \\
\hline Target & & Counter-flow diffusion flame \\
\hline Detailed chemistry & & DRM $22[20]$ \\
\hline Scalar dissipation rate & {$\left[\mathrm{s}^{-1}\right]$} & $10^{-4}-10^{3}$ \\
\hline Boundary temperature & {$[\mathrm{K}]$} & 600 \\
\hline
\end{tabular}

To construct the look-up tables, we supposed a laminar case in which variance does not have to be considered. Firstly, $Z_{2}$ was assigned values from zero to unity, and the overall fuel gas composition was determined according to Eq.6. Note that the flame does not ignite if $Z_{2}$ is set to unity because hydrogen is not included in the flame. Thus, the maximum value of $Z_{2}$ was set to 0.9 , i.e., less than 1.0. Fig. W shows the overall fuel gas composition as a function of $Z_{2}$. In this study, the one-dimensional calculations were conducted using $Z_{2}=0.0,0.2,0.5,0.7,0.8$ and 0.9 to cover a wide range of $Z_{2}$ coordinates in the look-up tables. The progress variable in this study was defined as the sum of the mass fractions of $\mathrm{CO}_{2}, \mathrm{H}_{2} \mathrm{O}$ and $\mathrm{H}_{2}$ :

$$
Y_{\mathrm{pv}}=Y_{\mathrm{CO}_{2}}+Y_{\mathrm{H}_{2} \mathrm{O}}+Y_{\mathrm{H}_{2}}
$$

As the fuel gas included $\mathrm{CO}$ irrespective of the value of $Z_{2}$, the mass fraction of $\mathrm{CO}$ was excluded from the progress variable as in previous studies [2.3] . Fig. 叉 provides the temperature, progress variable, and production rate of the progress variable as functions of $Z_{2}$ with a scalar dissipation rate of $1.0 \mathrm{~s}^{-1}$ and fuel gas temperature of $600 \mathrm{~K}$. The stoichiometric mixture moved toward fuel-rich conditions, and the maximum temperature decreased with increasing $Z_{2}$. The calculation results obtained using various scalar dissipation rates were tabulated along with the mixture fraction, progress variable, and $Z_{2}$ coordinates. Then, the progress variable was normalized according to the maximum and minimum 
progress variables at each mixture fraction point as follows:

$$
C=\frac{Y_{\mathrm{pv}}-Y_{\mathrm{pv}}^{\min }(Z)}{Y_{\mathrm{pv}}^{\max }-Y_{\mathrm{pv}}^{\min }(Z)} .
$$

For example, Fig. 3 shows the contour plots of the temperature and production rate of the progress variable in the $Z$ - $C$ plane extracted from the look-up table with $Z_{2}=0.0$ and $T_{\text {fuel }}=600 \mathrm{~K}$. The production rate of the progress variable increases steeply near the stoichiometric mixture, whereas the temperature gradually increases from the oxidant and fuel side to the stoichiometric mixture.

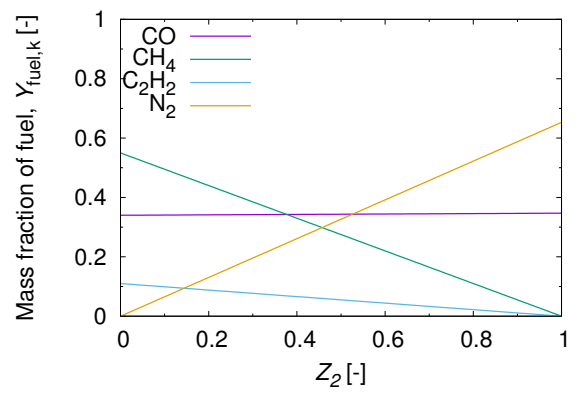

Fig 1. Fuel composition as a function of $Z_{2}$. 


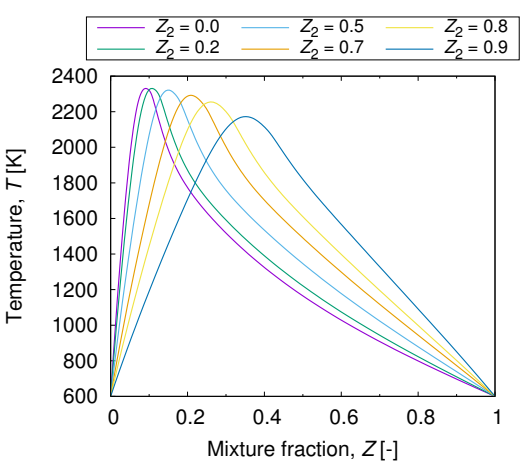

(a) temperature

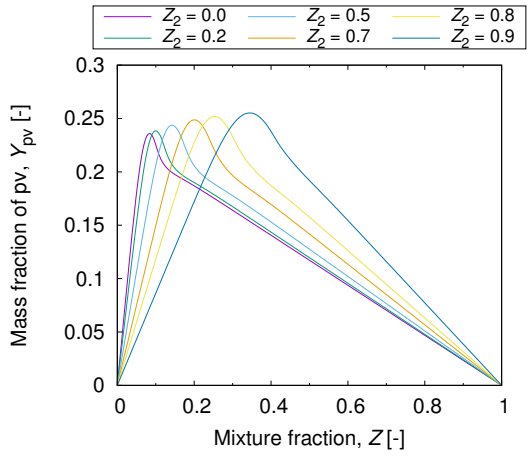

(b) progress variable

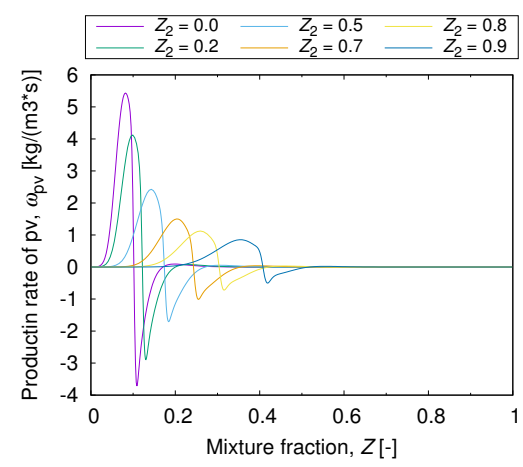

(c) production rate of the progress variable

Fig 2. One-dimensional steady counter-flow diffusion flame calculation results for the (a) temperature, (b) progress variable, and (c) production rate of the progress variable with $\chi_{s t}=1.0 \mathrm{~s}^{-1}$ and $T_{\text {fuel }}=600 \mathrm{~K}$. 


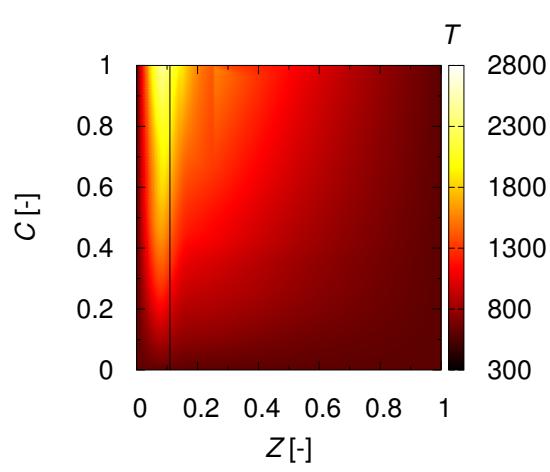

(a) temperature

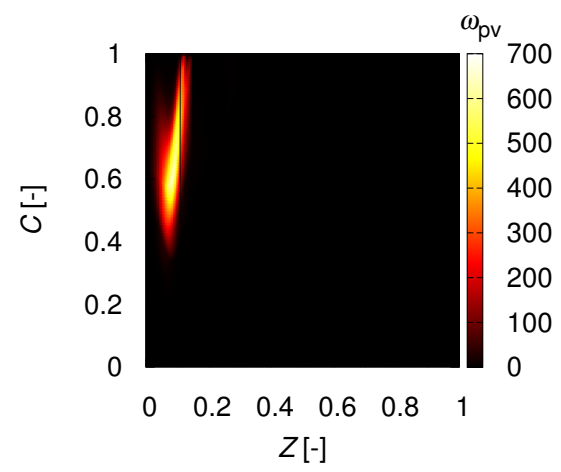

(b) production rate of the progress variable

Fig 3. Contour plots of the (a) temperature and (b) production rate of the progress variable in the $Z$ - $C$ plane extracted from the flamelet table with $Z_{2}=$ 0.0 and $T_{\text {fuel }}=600 \mathrm{~K}$. The solid line corresponds to the stoichiometric mixture.

By combining the numerical results for the various $Z_{2}$ values, the effects

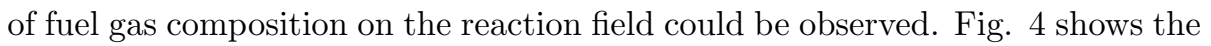
contour plots of the temperature and production rate of the progress variable in the $Z-Z_{2}$ plane extracted from the flamelet table with $C=0.5$ and $T_{\text {fuel }}=$ $600 \mathrm{~K}$. The high-temperature region moves to the fuel-rich area because the stoichiometric mixture fraction increases with increasing $Z_{2}$. This tendency is also observable in the production rate of the progress variable. 


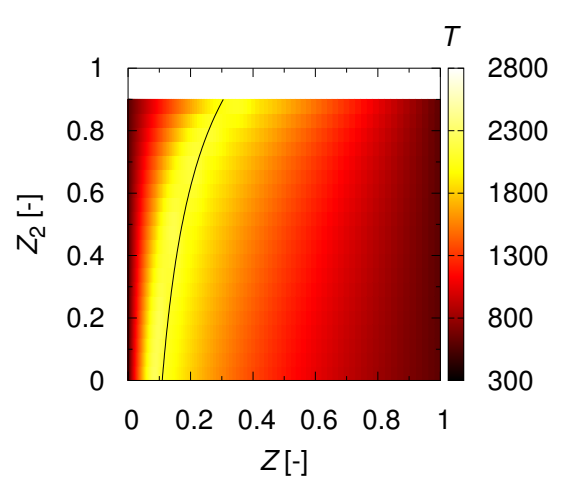

(a) temperature

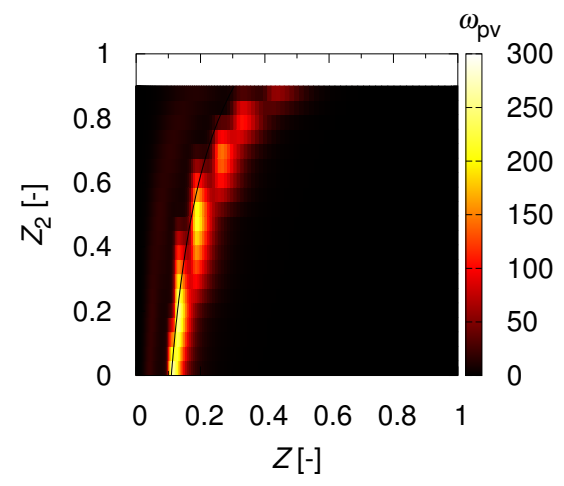

(b) production rate of the progress variable

Fig 4. Contour plots of the (a) temperature and (b) production rate of the progress variable in the $Z-Z_{2}$ plane extracted from the flamelet table with $C=$ 0.5 and $T_{\text {fuel }}=600 \mathrm{~K}$. The solid line corresponds to the stoichiometric mixture.

\subsection{Additional dimension for heat transfer between the gas phase and dispersed phase}

Generally, tabulated information such as gas temperature and chemical species was estimated in the environment without including "external effects" on the domain. In a certain domain in which the effects of heat loss/gain cannot be ignored, the change of energy should be included in the look-up tables. As a large amount of heat is exchanged between the gas phase and dispersed phase primarily via convective heat transfer, adiabatic flamelet solutions should not be used in pulverized coal combustion systems. To account for the effects of heat transfer between the two phases, enthalpy was added to representative quantities in the look-up tables, and additional combustion simulations were conducted under various enthalpy levels.

Several researchers have proposed methods of performing additional computations with the effects of heat loss. For example, Marracino and Lentini [24] constructed look-up tables based on flamelet equation solutions with reduced boundary temperature. They kept the boundary temperature at a realistic level by shrinking the solution domain (for example, $Z=0.01$ to $Z=0.99$ ) 
when they considered higher enthalpy defect levels. Hossain et al. [25] avoided unrealistically low temperatures by slightly modifying the fuel composition at the boundaries and achieved a realistic temperature without changing the solution domain. On the other hand, Kishimoto et al. [26] modified the source term in the energy equations and obtained flamelet data covering a wide range of enthalpy defects. In this method, the heat loss became larger in the hightemperature zone and smaller in the low-temperature zone near the boundary; therefore, the temperature dependence of the enthalpy defect yielded realistic heat loss in the solution domain. A similar concept was also used in the flameletgenerated manifold model [27]. In this study, the simplest method in which the boundary temperature was adjusted was used, as in previous work [1.3, [2.3]

In the base (i.e., adiabatic) conditions, the boundary temperature was assigned a value of $600 \mathrm{~K}$ on the fuel and oxidizer sides. To cover the entire range of enthalpy levels considered in the later CFD simulation, the boundary temperature was set to $100 \mathrm{~K}$ or $600 \mathrm{~K}$ on the oxidant side and $100-1500 \mathrm{~K}$ on the fuel side. Although the boundary temperature was decreased to an unrealistic level to cover all of the enthalpy levels that could be considered in the CFD simulation, the flamelet data in this region were not used in the simulation. Fig. 1 shows the enthalpy and temperature as functions of the mixture fraction with $Z_{2}=0.0$. The boundary temperature at the oxidant side was set to $600 \mathrm{~K}$ except in the case of $T_{\text {fuel }}=100 \mathrm{~K}$. As the temperature depends on the stoichiometric scalar dissipation rate, $\chi_{s t}$, the distribution with $\chi_{s t}=1.0 \mathrm{~s}^{-1}$ is presented in this figure as an example. In the counter-flow diffusion flame calculation with the assumption of a Lewis number of unity, the enthalpy linearly decreases (or increases) to the mixture fraction. Naturally, the enthalpy gradient decreases from the oxidant side to the fuel side as the fuel temperature increases. As the enthalpy range varies according to the mixture fraction in this method, the normalized enthalpy was introduced as follows:

$$
h_{n}\left(Z, Z_{2}\right)=\frac{h-h^{\min }\left(Z, Z_{2}\right)}{h^{\max }\left(Z, Z_{2}\right)-h^{\min }\left(Z, Z_{2}\right)} .
$$


Look-up tables for the gas temperature and production rate of the progress variable along the enthalpy axis are provided in Fig. 6. These quantities increase with increasing normalized enthalpy.

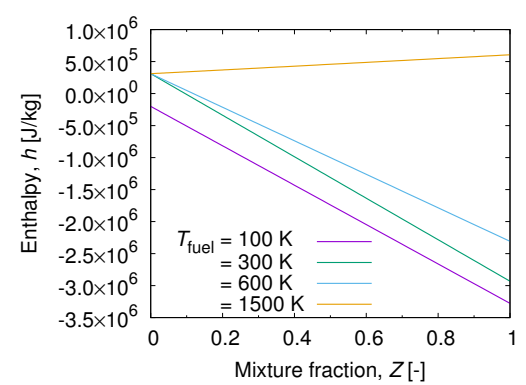

(a) enthalpy

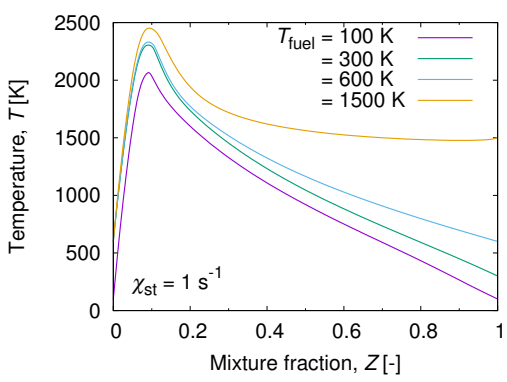

(b) temperature

Fig 5. Differences in (a) enthalpy and (b) temperature $\left(\chi_{s t}=1.0 \mathrm{~s}^{-1}\right)$ according to the boundary temperature at a fuel side in the case of $Z_{2}=0.0$. It is noted that the total enthalpy does not change by a scalar dissipation rate.

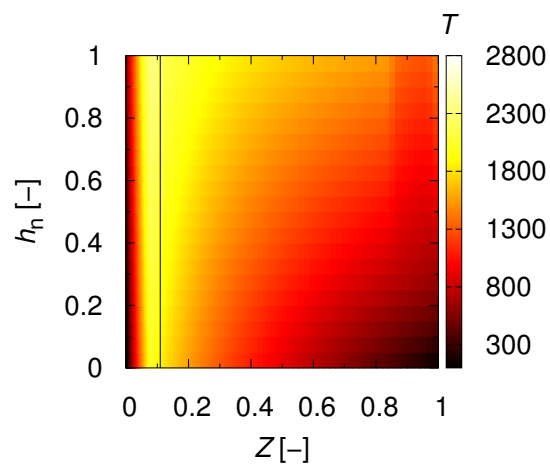

(a) temperature

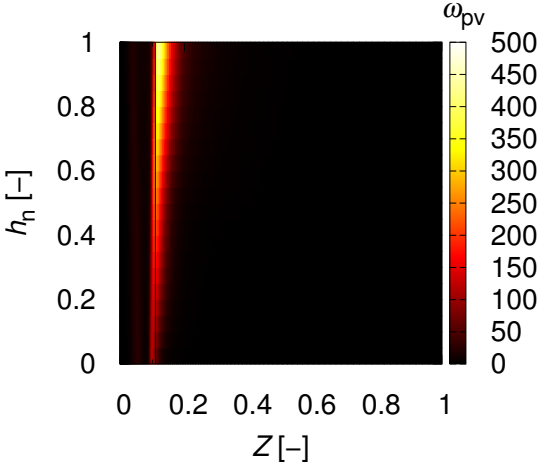

(b) production rate of the progress variable

Fig 6. Contour plots of the (a) temperature and (b) production rate of the progress variable in the $Z-h_{n}$ plane extracted from the flamelet table with $C=$ 0.5 and $Z_{2}=0.0$. The solid line corresponds to the stoichiometric mixture. 


\section{Laminar combustion simulation of counter-flow diffusion flame}

\subsection{Computational domain and numerical conditions}

The computational domain was the two-dimensional laminar counter-flow diffusion flame used in previous studies [2:3, [28, [29]. Fig. [ 7 shows the geometry and inlet conditions. Both the vertical and horizontal lengths of the computational domain are $20 \mathrm{~mm}$, and the domain was divided into $200 \times 200$ computational cells. The dependence of the mesh resolution was also checked, and we confirmed that the present number of computational cells was sufficient for the simulation, as shown in the appendix. Pulverized coal and air with a temperature of $600 \mathrm{~K}$ were supplied from the upper side, while only air was supplied from the lower side. The diameters of all of the injected particles were set to $5 \mu \mathrm{m}$. Table $\mathbf{B}$ lists the proximate and ultimate analysis results for the supplied Newlands coal. These values are also the same as those in previous studies [30, 31]. Table 4 summarizes the numerical conditions, which are the same as those employed by Wen et al. [2.3]. The strain rate was defined as

$$
a=\frac{\left|u_{\text {upper }}\right|+\left|u_{\text {lower }}\right|}{L},
$$




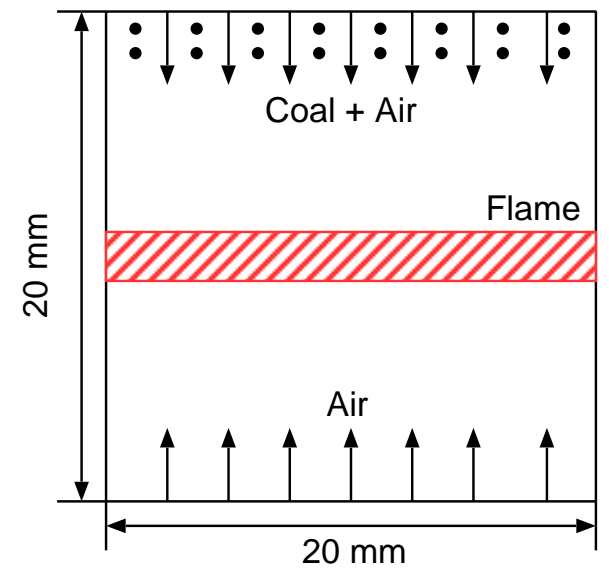

Fig 7. Schematic of the computational domain (reconstructed from [2:3]).

Table 3. Coal properties of Newlands coal.

\begin{tabular}{lcc}
\hline \multicolumn{3}{l}{ Proximate analysis (dry basis) } \\
\hline Ash & {$[\mathrm{wt} \%]$} & 15.2 \\
Volatile matter (VM) & {$[\mathrm{wt} \%]$} & 26.9 \\
Fixed carbon (FC) & {$[\mathrm{wt} \%]$} & 57.9 \\
\hline \multicolumn{2}{l}{ Ultimate analysis (dry basis) } \\
\hline $\mathrm{C}$ & {$[\mathrm{wt} \%]$} & 71.9 \\
$\mathrm{H}$ & {$[\mathrm{wt} \%]$} & 4.4 \\
$\mathrm{~N}$ & {$[\mathrm{wt} \%]$} & 1.5 \\
$\mathrm{~S}$ & {$[\mathrm{wt} \%]$} & 0.44 \\
$\mathrm{O}$ & {$[\mathrm{wt} \%]$} & 6.53 \\
Heating value (low) & {$[\mathrm{MJ} / \mathrm{kg}]$} & 28.1 \\
\hline
\end{tabular}


Table 4. Numerical conditions.

\begin{tabular}{lccc}
\hline & $\begin{array}{c}\text { Coal/air } \\
{[\mathrm{wt} \%]}\end{array}$ & $\begin{array}{c}\text { Strain rate, } a \\
{\left[\mathrm{~s}^{-1}\right]}\end{array}$ & $\begin{array}{c}\text { Inlet velocity } \\
{[\mathrm{m} / \mathrm{s}],}\end{array}$ \\
\hline Case 1 & - & 100 & 1.0 \\
Case 2 & 11.5 & 200 & 2.0 \\
Case 3 & 46.0 & 100 & 1.0 \\
Case 4 & 23.0 & 100 & 1.0 \\
\hline
\end{tabular}

\subsection{Governing equations and numerical method}

\subsubsection{Parcel approximation}

This study was based on the Euler-Lagrange approach. As the feed rate of pulverized coals is comparable to several billion particles in industrial pulverized coal combustors, it is impossible to track all of the particles due to the excessive computational cost. Consequently, the concept of "parcels" was introduced for the representative particles in the numerical simulation of splay and pulverized coal combustion. In the calculation of the effect of the dispersed phase on the gas phase, the number of particles represented by a parcel, called the "parcel number", was multiplied times the source term, and the actual conditions were reproduced in the simulation. The parcel number was calculated using

$$
P_{n u m, i}=\frac{F_{p} f_{m, i}}{m_{p, i} n_{i}},
$$

where $F_{p}, f_{m, i}, m_{p, i}, n_{i}$ are the total feed rate, mass fraction of particles with

diameter $i$, particle mass, and number of injected particles per one-step calculation, respectively. $F_{p} f_{m, i} / m_{p, i}$ corresponds to the number-based feed rate for particle diameter $i$.

\subsubsection{Governing equations of the dispersed phase}

The particle mass is decreased by devolatilization and char oxidation according to

$$
\frac{\mathrm{d} m_{p}}{\mathrm{~d} t}=-\left(\dot{m}_{p, \mathrm{devol}}+\dot{m}_{p, \mathrm{char}}\right)
$$


The coal particles move in the gas phase while receiving the drag and gravity forces as

$$
\frac{\mathrm{d} \mathbf{u}_{\mathbf{p}}}{\mathrm{d} t}=\frac{\left(\mathbf{u}-\mathbf{u}_{\mathbf{p}}\right)}{\tau_{p}}+\mathbf{g},
$$

where $\mathbf{u}$ and $\mathbf{u}_{\mathbf{p}}$ are gas and particle velocity vectors, respectively. The first term on the right-hand side (RHS) represents the drag force, and the second term on the RHS represents the gravitational force with the assumption that the gas density is much less than the particle density, $\rho \ll \rho_{p}$. $\tau_{p}$ is the particle relaxation time and is defined as follows [32]:

$$
\tau_{p}=\left(\frac{3}{4} \frac{\rho C_{D}}{\rho_{p} d_{p}}\left|r_{v}\right|\right)^{-1}
$$

where $C_{D}, d_{p}$ and $r_{v}$ are the drag force coefficient, particle diameter, and relative velocity between the gas and dispersed phases, respectively. The drag force coefficient was evaluated using the equation proposed by Crift and Gauvin [3.3] as

$$
C_{D}=\frac{24}{R e_{p}}\left(1+0.15 R e_{p}^{0.687}\right)+\frac{0.42}{1.0+4.25 \times 10^{4} R e_{p}^{-1.16}},
$$

where $R e_{p}$ is the particle Reynolds number defined as

$$
R e_{p}=\frac{\rho\left|r_{v}\right| d_{p}}{\mu}
$$

where $\mu$ is the gas viscosity. The coal particles injected into the combustion system are heated by convective and radiative heat transfer from a hot gas while generating heat by char reaction. This heat contributes to the temperature elevation itself. The particle energy equation is

$$
\begin{aligned}
m_{p} c_{p, p} \frac{\mathrm{d} T_{p}}{\mathrm{~d} t} & =h_{\text {conv }}\left(T-T_{p}\right) A_{p, \text { surface }} \\
& +\varepsilon_{p}\left(\frac{G}{4}-\sigma T_{p}^{4}\right) A_{p, \text { surface }}+\dot{q}_{\mathrm{char}}+\dot{q}_{\mathrm{devol}}
\end{aligned}
$$

where $A_{p, \text { surface }}, c_{p, p}, G, h_{c o n v}, T$ and $T_{p}$ are are the external surface area of the particle $\left(=\pi d_{p}^{2}\right)$, specific heat of the particle, incident radiation, convective heat transfer coefficient, gas temperature, and particle temperature, respectively. $\varepsilon_{p}$ and $\sigma$ are the particle emissivity and Stefan-Boltzmann constant $\left(=5.67 \times 10^{-8} \mathrm{~W} /\left(\mathrm{K}^{4} \cdot \mathrm{m}^{2}\right)\right)$, respectively. The particle emissivity was set to 
0.85. $\dot{q}_{\text {char }}$ and $\dot{q}_{\text {devol }}$ are the exothermic and endothermic heat, respectively, due to the chemical reactions of coal and were assumed to be $9.21 \times 10^{-6} \mathrm{~J} / \mathrm{kg}$ and $0.0 \mathrm{~J} / \mathrm{kg}$, respectively, which means that the endothermic heat by devolatilization was ignored, based on a previous study [14]. As shown in Eq. [7, all of the exothermic heat generated by char oxidation was conducted only into the dispersed phase in this study. If the reaction heat was conducted into the gas phase, it would be necessary to implement this effect in the one-dimensional cal-

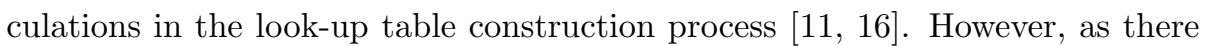
is ambiguity in the ratio of the heat conducted into the gas phase, heat transfer was allowed only in the direction of the dispersed phase.

The specific heat of the particles is one of the most important parameters in the particle heat-up process. Based on previous research [34, 35], Stöllinger et al.[36] evaluated the overall specific heat as the sum of those of the individual coal components:

$$
c_{p, p}=Y_{\mathrm{vol}} \cdot c_{p, \mathrm{vol}}+Y_{\mathrm{fc}} \cdot c_{p, \mathrm{fc}}+Y_{\mathrm{ash}} \cdot c_{p, \mathrm{ash}},
$$

where $c_{p, \text { ash }}, c_{p, \mathrm{fc}}$ and $c_{p, \mathrm{vol}}$ re the specific heats of ash, fixed carbon, and volatile, respectively, and were calculated based on Einstein's theory of the specific heats of solids, where the specific heat was recognized through molecular oscillators. Referring to this classical concept, Merrick proposed the following equation to estimate the specific heats of volatiles and fixed carbon [34]:

$$
\begin{aligned}
c_{p, \gamma} & =\frac{R}{W_{\gamma}}\left[g_{1}\left(\frac{380}{T_{p}}\right)+2 g_{1}\left(\frac{1800}{T_{p}}\right)\right], \\
g_{1}(x) & =\frac{e^{x}}{\left[\left(e^{x}-1\right) / x\right]^{2}},
\end{aligned}
$$

where $R$ and $W_{\gamma}$ are the gas constant and mean atomic weight of volatile matter and fixed carbon. The mean atomic weight of volatile matter, $W_{\mathrm{vol}}$ was assumed to have values of $5-8$ in previous studies [36, 37]. In this study, the mean atomic weight was calculated using the following equation:

$$
\frac{1}{W_{\mathrm{vol}}}=\sum_{i=1}^{5} \frac{y_{i}}{\mu_{i}},
$$


where $y_{i}$ is the mass fraction of carbon, oxygen, hydrogen, nitrogen, or sulfur in the volatile matter, which can be estimated from the proximate and ultimate analyses of the coal, and $\mu_{i}$ is the atomic weight of the corresponding element. In this study, $W_{\text {vol }}=5.934 \mathrm{~g} / \mathrm{mol}$ based on the calculations, while The mean atomic weight of fixed carbon, $W_{\mathrm{fc}}=12 \mathrm{~g} / \mathrm{mol}$. The specific heat of ash was calculated using

$$
c_{p, \text { ash }}=539.9+0.586 T_{p} \quad(\mathrm{~J} /(\mathrm{kg} \cdot \mathrm{K})) .
$$

The convective heat transfer coefficient in the particle energy equation, Eq. [0, was evaluated from the Nusselt number based on the equation of Ranz-Marshall [38]:

$$
N u=\frac{h_{\text {conv }} d_{p}}{\lambda}=2.0+0.552 \operatorname{Re}_{p}^{1 / 2} \operatorname{Pr}^{1 / 3},
$$

where $\operatorname{Pr}$ and $\lambda$ are the Prandtl number and thermal conductivity, respectively. $\operatorname{Pr}$ was set to 0.7 and $\lambda$ was retrieved from the look-up tables. The incident radiation in Eq. $\square$ was calculated using the P1 approximation method, as described in section 3.2 .5 .

\subsubsection{Modeling of chemical reactions of pulverized coals}

For the chemical reactions of pulverized coals, devolatilization and char oxidation were considered. Although there is the room for further discussion regarding the order of devolatilization and char oxidation [39], they were assumed to be independent of each other, i.e., it was assumed that char oxidation did not start until the devolatilization process was completed. Specifically, char oxidation could occur after $99.9 \%$ of the volatile matter had evolved from the coal particles in this study. The classical single first-order reaction model proposed by Badzioch and Hawskley [40] was used to calculate the devolatilization rate as follows:

$$
\dot{m}_{p, \text { devol }}=A_{\text {devol }} \exp \left(-\frac{E_{\text {devol }}}{R T_{p}}\right)\left(m_{\mathrm{vol}, 0}^{*}-m_{\mathrm{vol}}\right)
$$

where $A_{\text {devol }}$ and $E_{\text {devol }}$ are the pre-exponential factor and activation energy and were set to $4.474 \times 10^{3} \mathrm{~s}^{-1}$ and $1.9188 \times 10^{7} \mathrm{~J} / \mathrm{kmol}$, respectively. These values 
were obtained from previous studies [6, 16, 41]. $m_{\mathrm{vol}, 0}^{*}$ and $m_{\mathrm{vol}}$ are the initial amount of volatile matter in the coal, which is the amount of volatile matter releasable from the coal, and the released amount of the volatile matter at the elapsed time, respectively. Then, the difference, $\left(m_{\mathrm{vol}, 0}^{*}-m_{\mathrm{vol}}\right)$ corresponds to the residual of the volatile matter in the coal. There are several methods of particle diameter change during devolatilization: the particle diameter may remain constant [14, 42, 43] or expand as devolatilization progresses [36, 44]. When particle swelling is considered, an additional model parameter called the swelling coefficient is needed to represent the degree of swelling. Although the swelling coefficient exactly depends on the coal type and heating rate, it is difficult to perform experiments to determine the appropriate value. In this study, the particle diameter was assumed to be constant as the particle density varied.

Char was assumed to consist of only carbon, and the partial oxidation of char, which generates $\mathrm{CO}$, was taken into account in the char combustion. Generally, char combustion is separated into partial oxidation and full oxidation, where partial oxidation is dominant at temperatures above $1500 \mathrm{~K}$ [45-47]. The overall char oxidation rate depends on the following three rates: the chemical reaction rate at the particle surface, rate of oxygen transport during pore diffusion, and rate of oxygen transport from the bulk side to the particle surface. As the effect of the oxygen transport process on the overall reaction rate increases at higher temperatures, the mass transfer process of oxygen is often included in the model equation. The overall reaction rate of char is described by

$$
\dot{m}_{p, \text { char }}=p_{\mathrm{O}_{2}} A_{p, \text { surface }} \frac{K_{\mathrm{diff}} K_{\mathrm{kin}}}{K_{\mathrm{diff}}+K_{\mathrm{kin}}},
$$

where $K_{\text {diff }}, K_{\text {kin }}$ and $p_{\mathrm{O}_{2}}$ are the mass transfer rate coefficient of oxygen, chemical reaction rate coefficient, and partial pressure of the oxidant, respectively. In this study, the external surface reaction model [48] was used for the kinetic reaction model. The kinetic coefficient was described using the following equation:

$$
K_{\mathrm{kin}}=A_{\mathrm{char}} \exp \left(-\frac{E_{\mathrm{char}}}{R T_{p}}\right)
$$


where $A_{\text {char }}$ and $E_{\text {char }}$ are the pre-exponential factor and activation energy and were set to $1.1 \times 10^{-2} \mathrm{~kg} /\left(\mathrm{m}^{2} \cdot \mathrm{s} \cdot \mathrm{Pa}\right)$ and $5.0 \times 10^{7} \mathrm{~J} / \mathrm{kmol}$, respectively. Note that these values were also obtained from previous works [6, [6, 41]. As several model parameters are needed to analyze the pore diffusion process, the value of $K_{\text {diff }}$ used in this study was obtained considering only the mass transfer process from the bulk side to the particle surface. The mass transfer rate of oxygen including the only diffusion process was represented as [5, [2:3]:

$$
K_{\mathrm{diff}}=\frac{4.998 \times 10^{-12}}{d_{p}}\left(\frac{T_{p}+T}{2}\right)^{0.75},
$$

where the constant $4.998 \times 10^{-12}$ depends on the unit of the partial pressure of oxygen.

\subsubsection{Governing equations in the gas phase}

In the case with detailed chemistry, the gas phase was described by the mass, momentum, enthalpy, and chemical species transport equations as

$$
\begin{gathered}
\frac{\partial \rho}{\partial t}+\frac{\partial}{\partial x_{j}}\left(\rho u_{j}\right)=\dot{S}_{c}, \\
\frac{\partial}{\partial t}\left(\rho u_{i}\right)+\frac{\partial}{\partial x_{j}}\left(\rho u_{i} u_{j}\right) \\
=-\frac{\partial p}{\partial x_{i}}+\frac{\partial}{\partial x_{j}}\left[\mu\left(\frac{\partial u_{i}}{\partial x_{j}}+\frac{\partial u_{j}}{\partial x_{i}}-\frac{2}{3} \delta_{i j} \frac{\partial u_{k}}{\partial x_{k}}\right)\right]+\dot{S}_{u_{i}}, \\
\frac{\partial}{\partial t}(\rho h)+\frac{\partial}{\partial x_{j}}\left(\rho u_{j} h\right)=\frac{\partial}{\partial x_{j}}\left(\frac{\mu}{\sigma_{h}} \frac{\partial h}{\partial x_{j}}\right)-\nabla \cdot q_{\mathrm{trad}}+\dot{S}_{h}, \\
\frac{\partial}{\partial t}\left(\rho Y_{k}\right)+\frac{\partial}{\partial x_{j}}\left(\rho u_{j} Y_{k}\right)=\frac{\partial}{\partial x_{j}}\left(\frac{\mu}{\sigma_{y}} \frac{\partial Y_{k}}{\partial x_{j}}\right)+\dot{\omega}_{k}+\dot{S}_{Y_{k}},
\end{gathered}
$$

where $h, p, u_{i}, Y_{k}, \rho, \mu, \sigma_{h}, \sigma_{y}$, and $\dot{\omega}_{k}$ are the enthalpy, pressure, gas velocity in the $i$ direction, mass fraction of chemical species $k$, gas density, viscosity, Prandtl number, Schmidt number, and production rate of the chemical species, respectively. The Prandtl and Schmidt numbers were both set equal to 0.7. $-\nabla \cdot q_{\text {trad }}$ is the energy source term due to radiation. The specific description of 
this term is provided in section [3.2.5. $\dot{S}_{c}, \dot{S}_{h}, \dot{S}_{u_{i}}$ and $\dot{S}_{Y_{k}}$ are the source terms from the dispersed phase and were calculated using the particle-source-in-cell model [49]. In the FPV model, transport equations are solved for the volatile and char off-gas mixture fractions and the progress variable in addition to mass, momentum, and enthalpy. The forms of the additional equations are as follows:

$$
\begin{gathered}
\frac{\partial}{\partial t}\left(\rho Z_{\mathrm{vol}}\right)+\frac{\partial}{\partial x_{j}}\left(\rho u_{j} Z_{\mathrm{vol}}\right)=\frac{\partial}{\partial x_{j}}\left(\frac{\mu}{\sigma_{y}} \frac{\partial Z_{\mathrm{vol}}}{\partial x_{j}}\right)+\dot{S}_{Z_{\mathrm{vol}}}, \\
\frac{\partial}{\partial t}\left(\rho Z_{\mathrm{char}}\right)+\frac{\partial}{\partial x_{j}}\left(\rho u_{j} Z_{\mathrm{char}}\right)=\frac{\partial}{\partial x_{j}}\left(\frac{\mu}{\sigma_{y}} \frac{\partial Z_{\mathrm{char}}}{\partial x_{j}}\right)+\dot{S}_{Z_{\mathrm{char}}},
\end{gathered}
$$

245

$$
\frac{\partial}{\partial t}\left(\rho Y_{p v}\right)+\frac{\partial}{\partial x_{j}}\left(\rho u_{j} Y_{p v}\right)=\frac{\partial}{\partial x_{j}}\left(\frac{\mu}{\sigma_{y}} \frac{\partial Y_{p v}}{\partial x_{j}}\right)+\dot{\omega}_{Y_{p v}} .
$$

where $Y_{p v}, Z_{\text {char }}$ and $Z_{\mathrm{vol}}$ are the sum of the mass fractions of the progress variable, char off-gas mixture fraction, and volatile mixture fraction, respectively, and $\dot{S}_{Z_{\mathrm{char}}}$ and $\dot{S}_{Z_{\mathrm{vol}}}$ are the source terms from the dispersed phase.

The mass of the coal particles decreases with devolatilization and char oxidation, and mass generation was imposed on the mass transport equations in the gas phase. Then, the absolute value given to the gas phase was the summation of each parcel:

$$
\dot{S}_{c}=\frac{1}{V_{\text {cell }}}\left[\sum_{i=1}^{N_{p}}\left(\dot{m}_{p, \text { devol }, i} \times P_{\text {num }, i}\right)+\sum_{i=1}^{N_{p}}\left(\dot{m}_{p, \text { char }, i} \times P_{n u m, i}\right)\right],
$$

where $\dot{m}_{p, \text { char }}, \dot{m}_{p \text {,devol }}, N_{p}$ and $V_{\text {cell }}$ are the char oxidation rate, devolatilization rate, number of parcels, and cell volume, respectively. As the coal particle motion was obstructed by the drag force in the gas phase, the momentum added to the particle was returned to the gas phase according to the following equation:

$$
\dot{S}_{u},=\frac{1}{V_{\text {cell }}}\left[\sum_{i=1}^{N_{p}}\left(F_{p, \text { drag }, i} \times P_{n u m, i}\right)\right],
$$

where $F_{p, \text { drag }}$ is the received amount of the drag force from the particles and corresponds to the first term on the RHS of Eq. ㅍ.3. As the released chemical 
species have thermal and chemical energy, it was necessary to include them in the source term in the enthalpy transport equation as follows:

$$
\begin{array}{r}
\dot{S}_{h}=\frac{1}{V_{\text {cell }}}\left[\sum _ { i = 1 } ^ { N _ { p } } \left\{\left(-h_{\text {conv }}\left(T-T_{p, i}\right)+\dot{m}_{p, \text { devol }, i} h_{\mathrm{vol}}\right.\right.\right. \\
\left.\left.\left.+\dot{m}_{p, \text { char }, i} h_{\text {char }}^{*}\right) \times P_{\text {num }, i}\right\}\right],
\end{array}
$$

$$
\begin{array}{r}
\dot{S}_{Y_{k}}=\frac{1}{V_{\text {cell }}}\left[\sum_{i=1}^{N_{p}}\left(Y_{k, \mathrm{vol}} \dot{m}_{p, \mathrm{devol}, i} \times P_{\text {num }, i}\right)\right. \\
\left.+\sum_{i=1}^{N_{p}}\left(Y_{k, \mathrm{char}} \dot{m}_{p, \mathrm{char}, i} \times P_{\text {num }, i}\right)\right],
\end{array}
$$

where $h_{\mathrm{CO}}$ and $h_{\mathrm{O}_{2}}$ are the enthalpies of $\mathrm{CO}$ and $\mathrm{O}_{2}$, respectively, at the gas phase temperature. $h_{v o l}$ can also be estimated using the following equation:

$$
h_{v o l}=\sum_{k=1}^{N}\left(Y_{\mathrm{vol}, k} h_{\mathrm{vol}, k}\right)
$$

where $h_{\mathrm{vol}, k}$ is the enthalpy of the chemical species in the volatile gas at the particle temperature. The first term on the RHS of Eq. 37 represents the convective heat transfer between the gas and dispersed phases, whereas the second and third terms on the RHS represent the energy of the generated chemical species in the gas phase. The effect of radiation from the particle surface was included in the incident radiation transport equation, as expressed in section 3.2.5. The source term in the chemical species transport equation is as follows:

The source terms in the mixture fraction transport equations can be represented as

$$
\dot{S}_{Z_{\mathrm{vol}}}=\frac{1}{V_{\mathrm{cell}}}\left[\sum_{i=1}^{N_{p}}\left(\dot{m}_{p, \mathrm{devol}, i} \times P_{n u m, i}\right)\right],
$$




$$
\dot{S}_{Z_{\text {char }}}=\frac{1}{V_{\text {cell }}}\left[\sum_{i=1}^{N_{p}}\left(\dot{m}_{p, \text { char }, i}\left(1+S_{\mathrm{O}_{2}}+S_{\mathrm{N}_{2}}\right) \times P_{\text {num }, i}\right)\right] .
$$

Note that $S_{\mathrm{O}_{2}}$ and $S_{\mathrm{N}_{2}}$ are necessary in Eq. 42 because the mixture fraction

of the product gas by char combustion is defined as char off-gas, as described by Eq. 2 . This is the main difference from the original method of extending the FPV model for pulverized coal combustion that was described by Watanabe and Yamamoto [II].

\subsubsection{Radiation modeling}

The effect of radiation was described using the P1 approximation method $[50,51]$. In this method, the incident radiation, which is defined as the integral of the radiation intensity over solid angles, is transported according to the following equation:

$$
-\left(\alpha_{g}+\left\langle\alpha_{p}\right\rangle\right) G+4 \alpha_{g} \sigma T^{4}+4\left\langle E_{p}\right\rangle+\nabla \cdot\left(\Gamma_{G} \nabla G\right)=0
$$

where $\alpha_{g}$ and $\alpha_{p}$ are the absorption coefficients of gas and particles, respectively.

275 The first three terms on the left-hand side represent the effects of absorption, gas emission, and particle emission on the incident radiation. Based on previous studies [5, [2.3] $\alpha_{g}$ was set to 0.075 . The brackets \langle\rangle denote the particle-averaged values in each computational cell. $\left\langle\alpha_{p}\right\rangle$ was determined using

$$
\left\langle\alpha_{p}\right\rangle=\frac{1}{V_{\text {cell }}} \sum_{i=1}^{N_{p}}\left[\varepsilon_{p, i} A_{p, i} \times P_{\text {num }, i}\right],
$$

where $A_{p}$ is the projected area of the particle $\left(=\pi d_{p}^{2} / 4\right) . E_{p}$ is the emission

from the particles to the gas phase, and the average value was estimated using

$$
\left\langle E_{p}\right\rangle=\frac{1}{V_{\text {cell }}} \sum_{i=1}^{N_{p}}\left[\varepsilon_{p, i} A_{p, i} \sigma T_{p, i}^{4} \times P_{n u m, i}\right] .
$$

$\Gamma_{G}$ in Eq. 0.3 was derived using

$$
\Gamma_{G}=\frac{1}{3\left(\alpha_{g}+\left\langle\alpha_{p}\right\rangle+\left\langle s_{p}\right\rangle\right)},
$$


where $s_{p}$ is the scattering coefficient and the average value can be expressed as

$$
\left\langle s_{p}\right\rangle=\frac{1}{V_{\text {cell }}} \sum_{i=1}^{N_{p}}\left[\left(1-\sigma_{p, i}\right)\left(1-\varepsilon_{p, i}\right) A_{p, i} \times P_{n u m, i}\right],
$$

where $\sigma_{p}$ is the particle scattering factor and was calculated using the relationship $\sigma_{p}+\varepsilon_{p}=1$. As the scattering by the gas phase was assumed to be anisotropic, the gas scattering term was eliminated from Eq. 46. The radiation source term in Eq. 30 was

$$
-\nabla \cdot q_{\mathrm{trad}}=\alpha_{g}\left(G-4 \sigma T^{4}\right)
$$

\subsubsection{Numerical method}

In-house code that was verified previously [52, 53] was used to perform the CFD simulation via the finite volume method. Numerical solutions were obtained from steady-state calculations using the FPV model. The convective terms of the momentum and scalar transport equations were spatially discretized using the total variational diminishing (TVD) scheme with a min-mod limiter function [54], while the second-order central differential scheme was used for the diffusion terms. The pressure and velocity were coupled according to the semiimplicit method for the pressure-linked equation (SIMPLE) algorithm [55]. In this algorithm, the convective and diffusion terms of the momentum equations were calculated implicitly, and iterative computations were conducted until the residuals fell below $10^{-5}$. The pressure correction equation, which is written in the type of Poisson equation, and the other equations were solved using the 300 Algebraic Multigrid Solver (AMGS) [56] and bi-conjugate gradient stabilized method with polynomial preconditioning (BiCGSTAB) [57], respectively. As the governing equation of the incident radiation also corresponds to the Poisson equation, the AMGS was used.

On the other hand, the CFD simulation with detailed chemistry was performed with unsteady calculations because the ordinary differential equations must be solved with appropriate time steps, which means that it is impossible to perform steady calculations with infinitely long time steps. The momentum 
equations were integrated over time using the second-order Adams-Bashforth method, while the other transport equations were solved implicitly using the solver. The convective and diffusion terms of the governing equations were discretized in the same manner as in the FPV model. The net production rate of each chemical species was obtained by solving the ordinary differential equations of the chemical species with the VODE package [58]. For the pressure-velocity coupling scheme, the simplified marker and cell (SMAC) method [5.9] was used because the iterative calculations were not necessary and the calculation time could be minimized. The solvers for the governing equations were also the same as those in the FPV model. The time step was determined by restricting the Courant number to a maximum of 0.3 , and the calculation time was set to $0.05 \mathrm{~s}$ in physical time, which is sufficiently long to reach a steady state in the present domain.

\section{Results and discussion}

\subsection{Verification of volatile gas combustion}

In Case 1, the prediction accuracy of the look-up tables was evaluated for only volatile combustion by simulation. In this case, the volatile gas compositions, i.e., $Z=1$ and $Z_{2}=0$, were given to the upper side as the boundary conditions, while the boundary conditions of the lower side were the same as in the other cases. Fig. $\square$ presents the axial distributions of the major chemical species and gas temperature. All of the variables, including the mass fractions of the minor species such as $\mathrm{H}_{2}$ and $\mathrm{OH}$, in the detailed chemistry can be well represented by the FPV model. Comparison of the FPV model solutions to the detailed chemistry results demonstrates the usability of the look-up tables for the pulverized coal combustion simulation with the FPV model. 


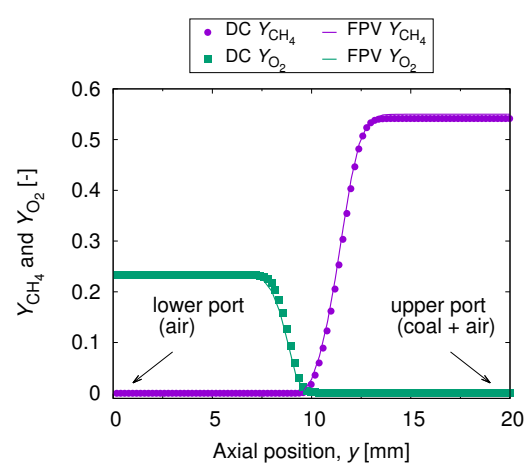

(a) $\mathrm{CH}_{4}$ and $\mathrm{O}_{2}$

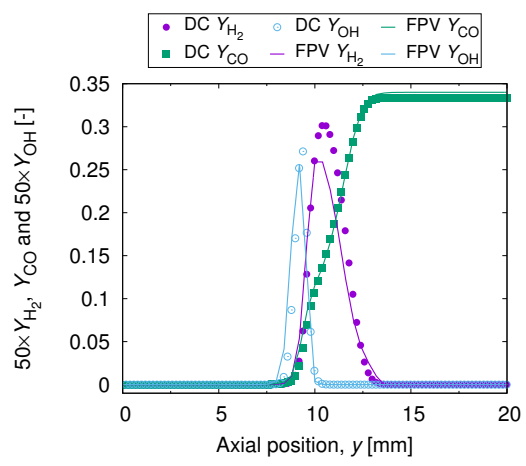

(c) $\mathrm{H}_{2}, \mathrm{CO}$ and $\mathrm{OH}$

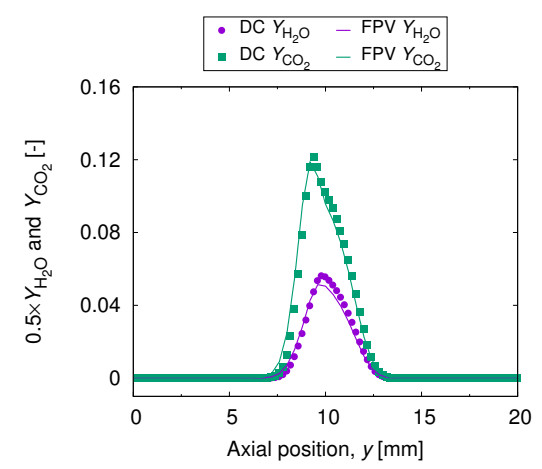

(b) $\mathrm{H}_{2} \mathrm{O}$ and $\mathrm{CO}_{2}$

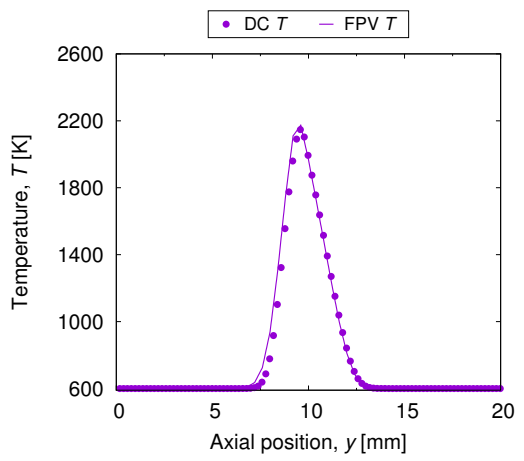

(d) gas temperature

Fig 8. Comparison of the axial profiles of the mass fractions of (a) $\mathrm{CH}_{4}$ and $\mathrm{O}_{2}$, (b) $\mathrm{H}_{2} \mathrm{O}$ and $\mathrm{CO}_{2}$, and (c) $\mathrm{H}_{2}, \mathrm{CO}$ and $\mathrm{OH}$ and (d) the gas temperature between the detailed chemistry and FPV model in only gas-phase combustion along the central axis. The axial positions of $y=0.0$ and $20 \mathrm{~mm}$ correspond to the oxidant and fuel boundaries, respectively.

\subsection{Overview of the counter-flow diffusion flame of pulverized coal particles}

Using the calculation results with the detailed chemistry, the flame structure

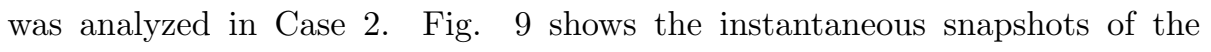
variables in the $x-y$ plane. To clarify the combustion mode in the counter-flow diffusion flame, the $F I[60]$ was introduced as

$$
F I=\nabla Y_{\text {fuel }} \cdot \nabla Y_{\text {ox }}
$$


where $Y_{\text {fuel }}$ and $Y_{\text {ox }}$ denote the mass fractions of the fuel and oxidant gas, respectively. The fuel was defined as $\mathrm{CH}_{4}, \mathrm{C}_{2} \mathrm{H}_{2}$ and $\mathrm{CO}$, while the oxidant gas was $\mathrm{O}_{2}$. The FI identifies the local combustion mode based on the directions of the fuel and oxidant gradients. If both gases evolve in the same direction, i.e., if the $F I$ is positive, the combustion mode is regarded as premixed combustion. Meanwhile, the combustion mode is regarded as nonpremixed in regions in which the $F I$ is negative. However, there is the concern of detecting unreacted regions because the combustion mode is identified only by the directions of the fuel and oxidant gradients in this indicator. To avoid this problem, the region in which the production rate of the progress variable $\dot{\omega}_{\mathrm{pv}}$ was less than $0.01 \%$ of the maximum value was removed from the FI calculation region; in other words, the FI in the cells with $\dot{\omega}_{\mathrm{pv}}<0.01 \% \dot{\omega}_{\mathrm{pv}}^{\max }$ became zero.

350 As the coal particles were supplied with a temperature of $600 \mathrm{~K}$, which corresponds to the devolatilization temperature, the coal gradually released volatile matter, and the release ratio reached almost $100 \%$ at $y=0.0 \mathrm{~mm}$. The magnitude of the vertical velocity steeply increased due to the volatile gas combustion because this region corresponds to the area in which the temperature begins to increase, as shown in Fig. $\mathbf{9}(\mathrm{c})$. The positive $F I$ in the same region suggests that the released volatile matter reacted with the oxygen in the career gas of the coal in the premixed combustion mode. The released volatile should instantly be consumed and converted into the combustion products because the FI steeply decreases to zero just downstream from the premixed combustion region. Moving further downstream, the FI continues to be zero, suggesting that chemical reaction does not occur in the middle parts of the high-temperature region near $y=0 \mathrm{~mm}$. As will be described later, it was confirmed that nearly all of the oxygen was consumed in the premixed combustion region even though the devolatilization from the coal was not completed. Thus, the chemical reaction should stop due to the lack of oxygen in this region. However, the FI significantly decreases, to less than zero, further downstream, which means that nonpremixed combustion occurs in this region. The reason for the generation of the nonpremixed combustion mode is expressed by the steep increase in $Z_{2}$ 
(see Fig. Q(e)). Char combustion started at the same time as the end of devolatilization, and the char off-gas reacted with the oxygen in the air supplied from the opposite side. 


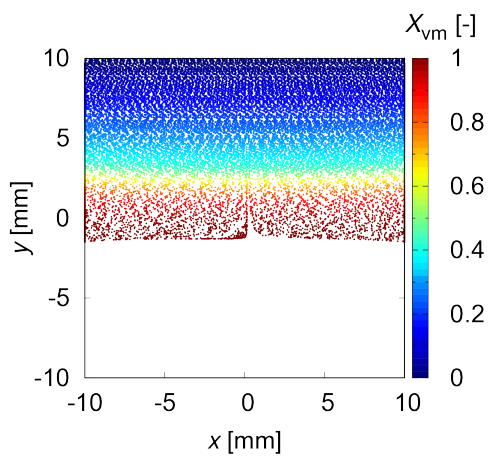

(a) coal particles colored according to $X_{\mathrm{vm}}$

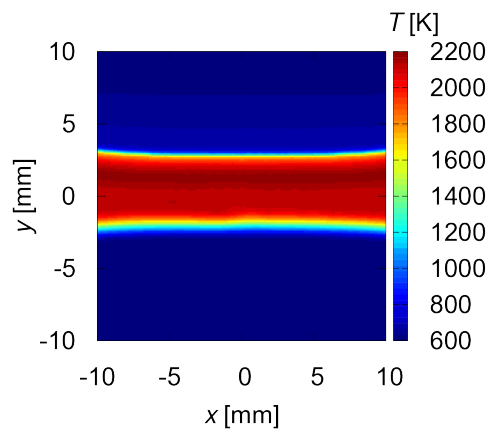

(c) $T$

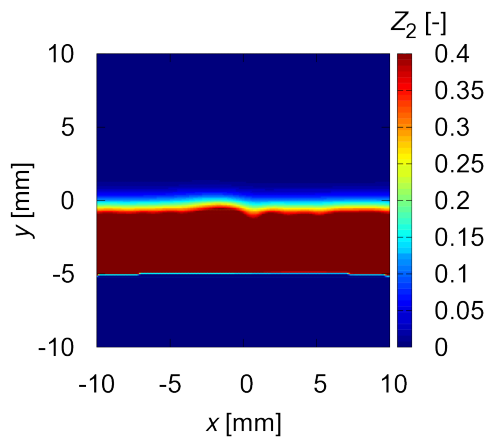

(e) $Z_{2}$

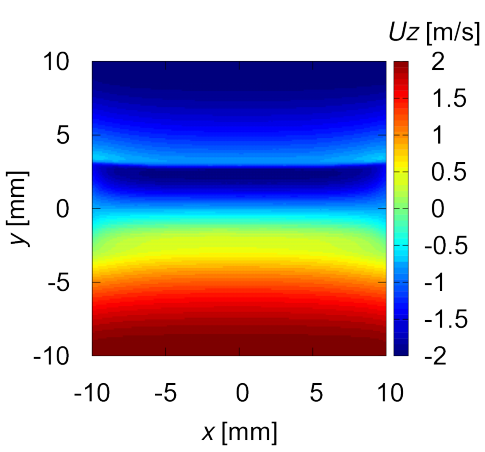

(b) $U_{z}$

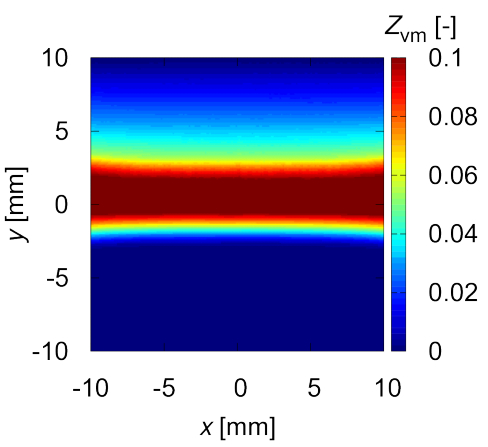

(d) $Z_{\mathrm{vm}}$

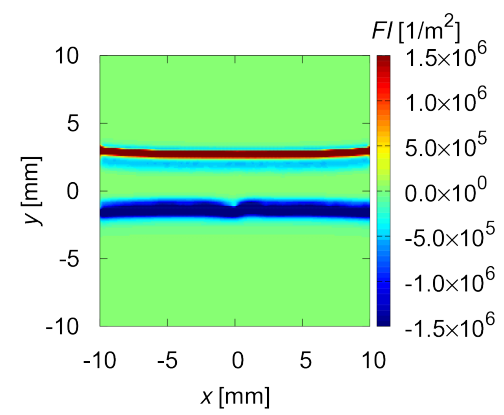

(f) $F I$

Fig 9. Instantaneous distributions of (a) coal particles colored according to the release ratio of volatile matter, (b) vertical velocity, (c) gas temperature, (d) mixture fraction of volatile matter, (e) $Z_{2}$, and (f) $F I$ with detailed chemistry in Case 2 at an elapsed time of $0.05 \mathrm{~s}$. 
Fig. 10 shows shows scatter plots of the gas temperature as a function of the mixture fraction in Case 2. Firstly, the reaction process of the coal will be traced in the mixture fraction space using Fig. س⿴囗十 (a). The injected particles with a temperature of $600 \mathrm{~K}$ began to release volatile matter, which ignited at a certain position. Although the gas temperature rapidly increased immediately after the ignition, the temperature elevation was reduced near $Z=0.1$, which is close to the stoichiometric mixture of the volatile gas flame, $Z_{s t}=0.10932$. Furthermore, the temperature of the gas phase remained near the stoichiometric mixture for a while, because the amount of $\mathrm{O}_{2}$ was insufficient to consume the additional volatile matter released by the coal particles. This region corresponds only to the high-temperature region, as shown in Fig. ㅁ(c). The higher FI in this region indicates that the combustion of volatile matter occurred in the premixed mode. When the devolatilization was completed, char combustion started; this procedure is represented in the latter stage of the combustion series in the upper branch in Fig. سు(a). The gas temperature in this region increases slightly with increasing $Z_{2}$ because the exothermic heat was generated by char oxidation and contributed to the temperature elevation in the gas phase through convective heat transfer. In contrast to the volatile combustion, the chemical reaction of the char off-gas occurred in the nonpremixed mode because the $F I$ was further below zero in this region. 


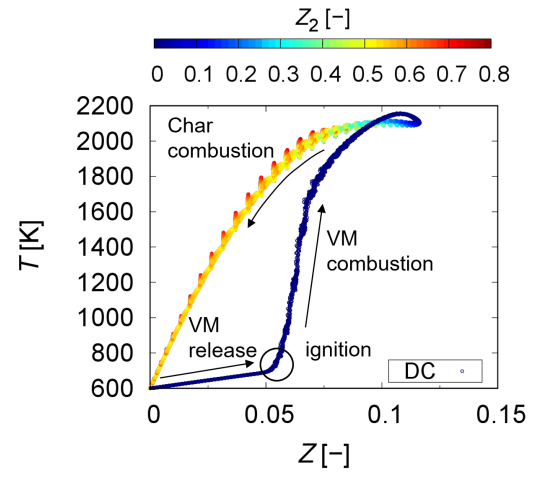

(a) colored according to $Z_{2}$

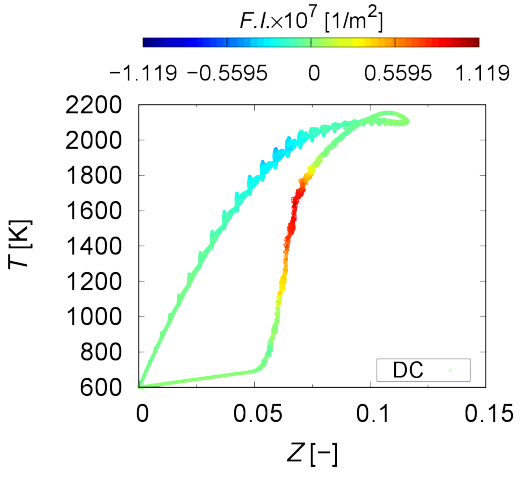

(b) colored according to $F I$

Fig 10. Scatter plots of gas temperature as a function of mixture fraction in Case 2 with detailed chemistry colored according to (a) $Z_{2}$ and (b) FI. The plots were extracted from the instantaneous distribution at an elapsed time of $0.05 \mathrm{~s}$.

\subsection{Effects of the strain rate and feed rate of coal particles on the flame structure}

The effects of the strain rate and feed rate of the coal particles on the flame structure were assessed by comparing the series of numerical results in Cases 2-4. Fig. $\square$ shows the instantaneous distributions of the gas temperature in these cases. Although the feed rate of coal is the same between Cases 2 and 4 , the inlet velocity (or strain rate) in Case 2 is twice as large as that in Case 4. Because of this difference, the residence time of the coal particles in Case 2 is shorter than that in Case 4. The high-temperature region becomes narrower in Case 4 because the flame temperature decreased due to the fuel rich conditions and local quenching effects due to the heat transfer between the gas and dispersed phases. In addition, the decrease in the strain rate moderated the temperature elevation on the upper side and significantly extended the ignition delay of the coal particles. This extended ignition delay in Case 4 is quite interesting because the residence time of the coal particles from the inlet to the high-temperature region should be longer than that in Case 2. As the feed rate of the coal increases, the high-temperature region becomes thinner, as can be 
seen by comparing Cases 3 and 4, because the increased momentum with increasing feed rate pushed the high-temperature region further downstream.

Fig. ए2 shows the axial distributions of the mixture fraction and gas temperature in the respective cases. From the upper port at $y=20 \mathrm{~mm}$, the mixture fraction linearly increases because the coal particles were supplied with a temperature of $600 \mathrm{~K}$. The release rate of volatile matter, which corresponds to the gradient of the mixture fraction, increases as the coal/air ratio increases. In Case 2, the gentle peak of the mixture fraction is located near the stoichiometric mixture fraction of the volatile gas flame; therefore, the high-temperature region is broader than in the other cases, as shown in Fig. ए2(b). Focusing on the gas temperature distribution upstream in front of the peaks, it can be seen that the temperature locally decreases in Case 3 and is slightly lower than that in Case 4. The effect of local quenching associated with heating and devolatilization process becomes larger as the feed rate of the coal particles increases, resulting in a temperature decrease and thinner flame.

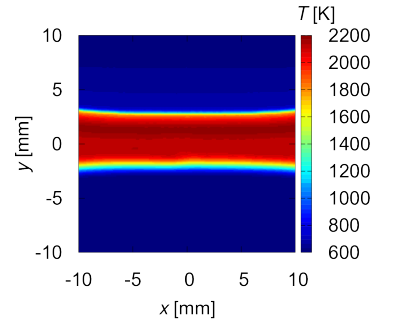

(a) Case $2(\mathrm{coal} /$ air $=0.115)$

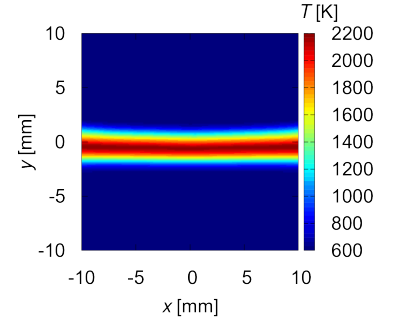

(b) Case $3($ coal/air $=0.46)$

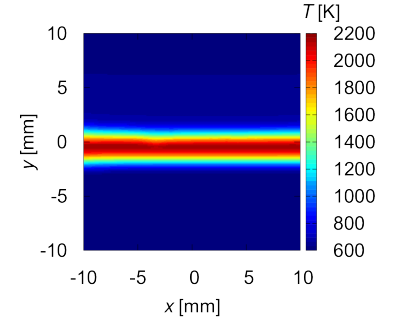

(c) Case 4 (coal/air $=0.23)$

Fig 11. Instantaneous gas temperature distributions with detailed chemistry in (a) Case 2 (coal/air $=0.115)$, (b) Case 3 (coal/air $=0.46)$, and (c) Case 4 $(\mathrm{coal} /$ air $=0.23)$ at an elapsed time of $0.05 \mathrm{~s}$. 


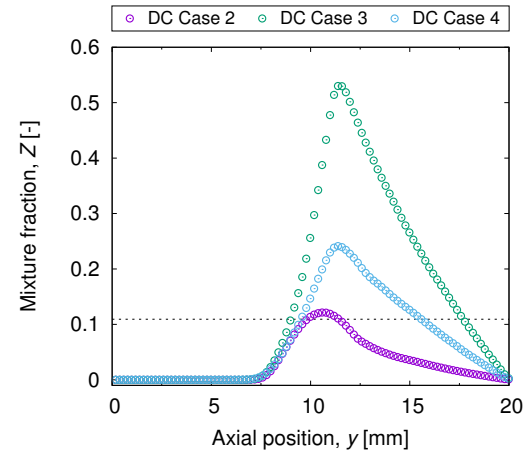

(a) mixture fraction

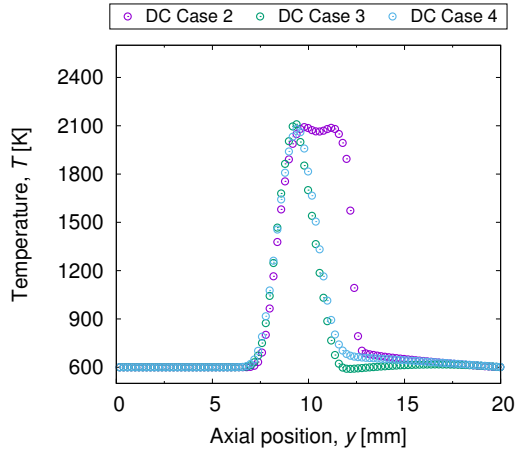

(b) gas temperature

Fig 12. Axial distributions of the (a) instantaneous mixture fraction and (b) gas temperature in Cases 2-4 at an elapsed time of $0.05 \mathrm{~s}$. The horizontal dashed line in the mixture fraction profile denotes the stoichiometric mixture fraction of the volatile gas flame.

Fig. [3] shows the instantaneous distributions of the FI in the respective cases. There are regions in which the $F I$ is positive and negative irrespective of the calculation conditions in this study, which means that the premixed and nonpremixed combustion modes coexisted in the flame. Premixed combustion should occur in a wider region in Case 4 than in Case 2 because the concentration of volatile gas is higher and a longer distance is required for volatile gas combustion. The intervals of regions with positive and negative $F I$ s become smaller in Case 4. In Case 2, the volatile matter reacted with oxygen in the carrier gas and the combustion was completed before the stagnation plane; therefore, there is a certain distance before the combustion of the char off-gas begins. On the other hand, the residence time of the coal particles is longer in Case 4 than in Case 2, resulting in the sudden evolution of a large amount of volatile matter at once. Unburnt fuel or char off-gas generated in a late stage was transported to the stagnation plane and reacted with oxygen supplied from the opposite side. In this case, the combustion mode became nonpremixed because the fuel and oxidant evolved in the opposite direction. 


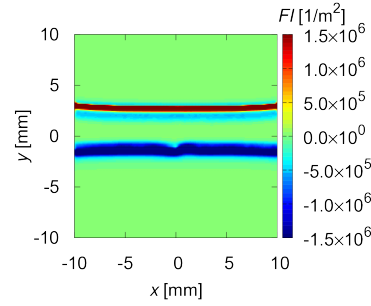

(a) Case 2 (coal/air $=0.115)$

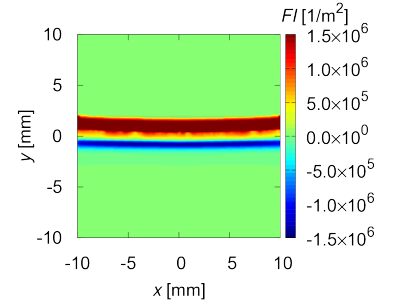

(b) Case $3(\mathrm{coal} / \mathrm{air}=0.46)$

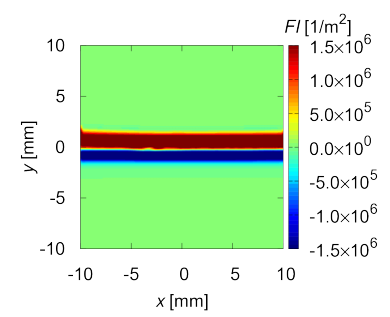

(c) Case 4 (coal/air $=0.23)$

Fig 13. Instantaneous distribution of $F I$ with detailed chemistry in (a) Case $2(\mathrm{coal} / \mathrm{air}=0.115),(\mathrm{b})$ Case $3(\mathrm{coal} / \mathrm{air}=0.46)$, and $(\mathrm{c})$ Case $4(\mathrm{coal} / \mathrm{air}=$ $0.23)$ at an elapsed time of $0.05 \mathrm{~s}$.

Fig. [4] compares the scatter plots of gas temperature and FI in Cases 2-4. All of the scatter plots show similar shapes irrespective of the calculation conditions in this study, indicating that the combustion progresses in the direction of right-handed rotation of the scatter plots, as shown in Fig. ㅁ⒜. However, there are some differences; for example, the gas temperature in Case 4 does not increase during the devolatilization process, which corresponds to the lower branch, but it does increase slightly in Cases 2 and 3, because the amount of energy consumed by the dispersed phase increased with increasing coal/air ratio. Another difference is evident in the scatter plots of the FI. Both the premixed and nonpremixed combustion regions move to the fuel side, and the peak becomes wider with increasing coal/air ratio. Notably, the order of magnitude of the width of the combustion region seems to differ from that in Fig. 103 because the width was stretched and displayed in the mixture fraction space. 


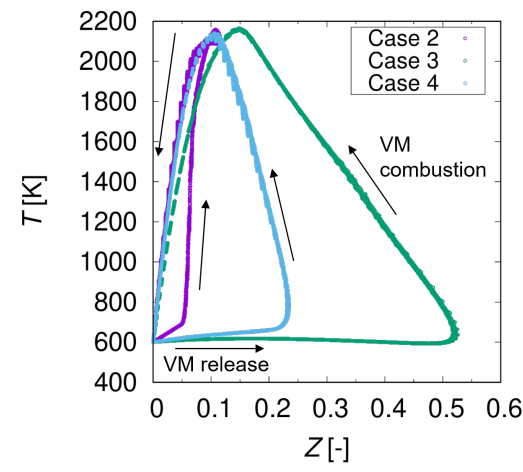

(a) gas temperature

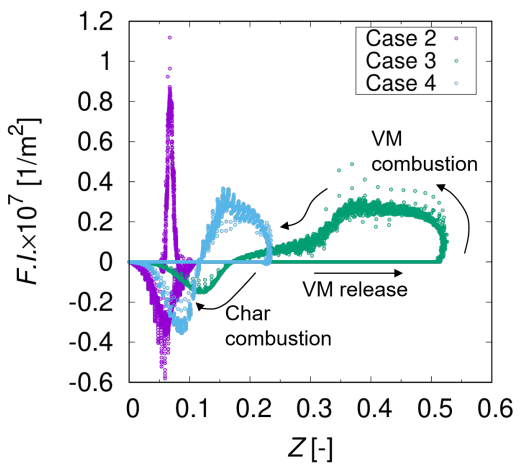

(b) FI

Fig 14. Scatter plots of (a) gas temperature and (b) FI as functions of the mixture fraction in Cases 2-4. The plots were extracted from the instantaneous distribution at an elapsed time of $0.05 \mathrm{~s}$.

The above analyses are briefly summarized in this paragraph. The volatile combustion and char off-gas combustion exhibited different combustion modes, i.e., premixed or nonpremixed. As this unique character was not observed in the volatile flame, the following section also addresses whether the FPV model can represent two-stage combustion. In terms of multi-phase combustion, the effect of local quenching on the gas phase is not small, especially in the non-reacting zone, e.g., the high-temperature zone in Case 2 and the devolatilization process in Case 4. This finding suggests that the enthalpy defect implemented in the look-up tables significantly impacts the prediction accuracy in the FPV model in pulverized coal combustion.

\subsection{Comparison of the numerical solutions obtained using detailed chemistry and the FPV model}

The comparison of the numerical solutions obtained using detailed chemistry to the results of the FPV model validated the applicability of the FPV model to pulverized coal combustion. The validation was separated into a priori and a posteriori tests in this study. The detailed procedure of each validation test 
is provided in Fig. ㄷ. In the a priori test, the representative variables, which

were used when the thermochemical quantities were retrieved from the look-up tables, were obtained from the transport equation of each chemical species in the detailed chemistry; thus, the prediction accuracy of the look-up tables was evaluated in this test. Note that it was necessary to determine the mixture fractions of volatile matter and char off-gas to identify the fuel gas resources, namely, devolatilization or char combustion. In contrast, the representative variables were directly obtained from the transport equation itself in the a posteriori test. The overall concept of this approach including the accuracy of the look-up tables was comprehensively assessed in this test. To identify the numerical results obtained using the two types of FPV models, the models are designated as the " a priori FPV model" and "a posteriori FPV model" in a later section of this paper.

(1) a priori test

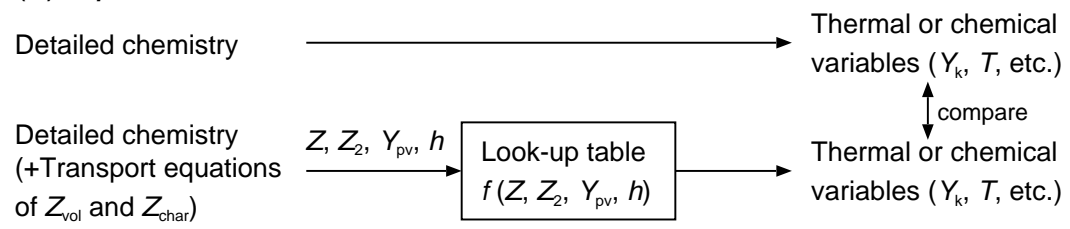

(2) a posteriori test

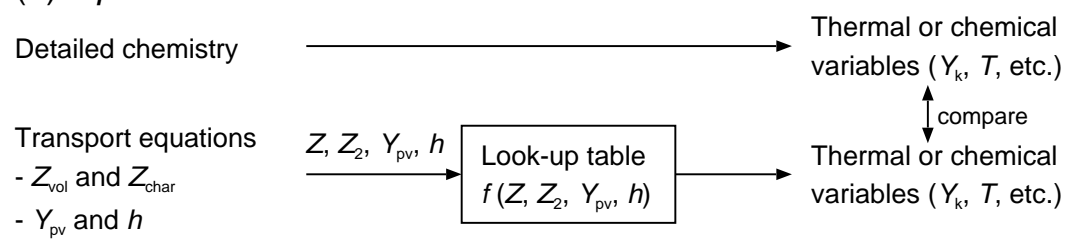

Fig 15. Schematic of a priori and a posteriori tests.

\subsection{Evaluation of the look-up table by a priori test}

Fig. $[6$ shows the distributions of the chemical species and gas temperature predicted by the detailed chemistry and a priori FPV model along the central axis in Case 2. The mass fraction of $\mathrm{CH}_{4}$ gradually increases downstream from $y=20 \mathrm{~mm}$, where the pulverized coal was injected, and suddenly decreases at $y$ $=12.5 \mathrm{~mm}$. As the mass fraction of $\mathrm{O}_{2}$ also decreases at this point, the sudden 
changes in $\mathrm{CH}_{4}$ and $\mathrm{O}_{2}$ indicate that volatile combustion started there. The small peak slightly downstream should be attributable to the coal particles for which devolatilization was not completed. The mass fraction of $\mathrm{CO}_{2}$ decreases at $y=10 \mathrm{~mm}$, although that of $\mathrm{H}_{2} \mathrm{O}$ remains constant. Given that the mass fraction $\mathrm{O}_{2}$ is almost zero at $y=10 \mathrm{~mm}$, fuel combustion should not occur at $y=10 \mathrm{~mm}$ in the domain. This estimation is consistent with the bimodal distribution of mass fraction of $\mathrm{OH}$ across the high-temperature region.

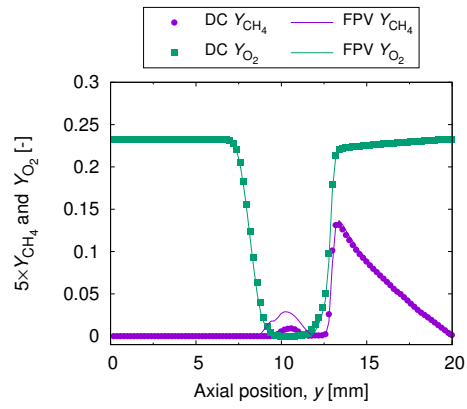

(a) $\mathrm{CH}_{4}$ and $\mathrm{O}_{2}$

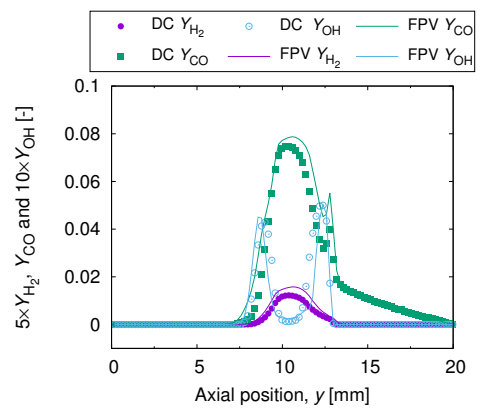

(c) $\mathrm{H}_{2}, \mathrm{CO}$ and $\mathrm{OH}$

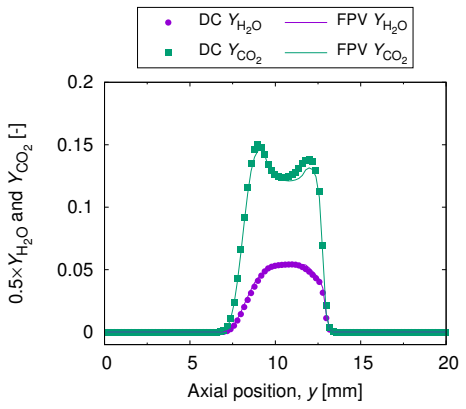

(b) $\mathrm{H}_{2} \mathrm{O}$ and $\mathrm{CO}_{2}$

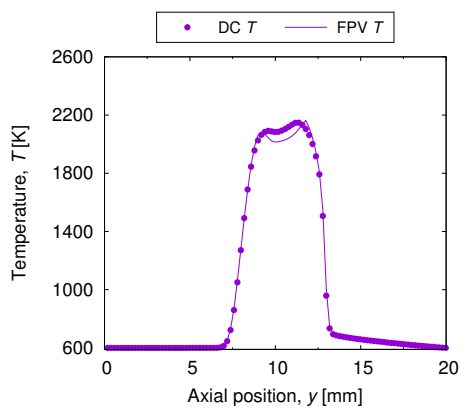

(d) gas temperature

Fig 16. Comparison of the axial profiles of the mass fractions of (a) $\mathrm{CH}_{4}$ and $\mathrm{O}_{2}$, (b) $\mathrm{H}_{2} \mathrm{O}$ and $\mathrm{CO}_{2}$, and (c) $\mathrm{H}_{2}, \mathrm{CO}$ and $\mathrm{OH}$ and (d) the gas temperature between the a priori FPV model and detailed chemistry in Case 2 at an elapsed time of $0.05 \mathrm{~s}$. The axial position represented along the horizontal axis is the distance from the lower of the computational domain. 
4.6. Evaluation of the FPV model in pulverized coal combustion by a posteriori test

Fig. $\square$ shows the distributions of the chemical species and gas temperature predicted by the detailed chemistry and a posteriori FPV model along the central axis in Case 2. Although the prediction accuracy of the a posteriori FPV model is slightly inferior to that of the a priori FPV model, the results of the a posteriori FPV model exhibit the same overall tendencies as the detailed chemistry results. Comparison of the temperature near $y=10 \mathrm{~mm}$ between the detailed chemistry and a posteriori FPV model highlights the larger local quenching effects in the a posteriori FPV model. Given that the results of the a priori FPV model deviate less than the a posteriori FPV model results from the detailed chemistry, the quantitative discrepancies in the a posteriori FPV model are attributable to the difference of the progress variable (specifically, the production rate of the progress variable), which can be obtained from the summation of the chemical products or look-up tables. To confirm this inference, the distributions of the representative variables are shown in Fig. 188. The production rate of the progress variable is definitely overestimated in the a posteriori FPV model, and the mass fraction of the progress variable is slightly larger than that in the detailed chemistry. As the look-up tables were constructed from the steady-state flamelet, thermochemical quantities with the conditions of the burnt state were provided in the gas phase, resulting in increased generation of the progress variables. Note that these characteristics of the FPV model have been reported previously [II, [2.2, 6I]. This effect should be related to the departure of the enthalpy from that in the detailed chemistry. The enthalpy level in the a posteriori FPV model gradually decreases, while it is almost constant in the detailed chemistry. The earlier decrease in enthalpy indicates earlier devolatilization in the a posteriori FPV model, resulting in a relatively large difference in enthalpy near $y=0 \mathrm{~mm}$. However, the a posteriori FPV model captures the overall tendencies of the detailed chemistry well. 


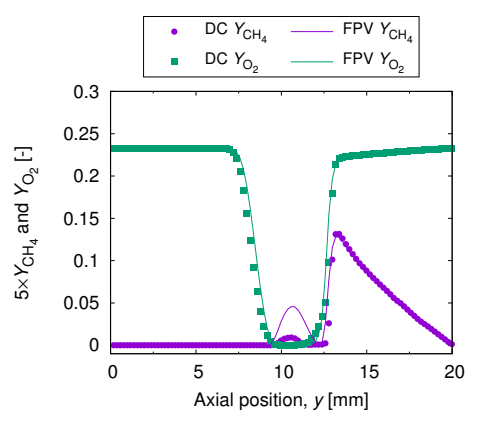

(a) $\mathrm{CH}_{4}$ and $\mathrm{O}_{2}$

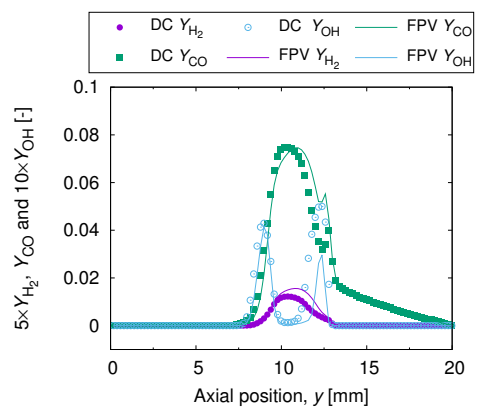

(c) $\mathrm{H}_{2}, \mathrm{CO}$ and $\mathrm{OH}$

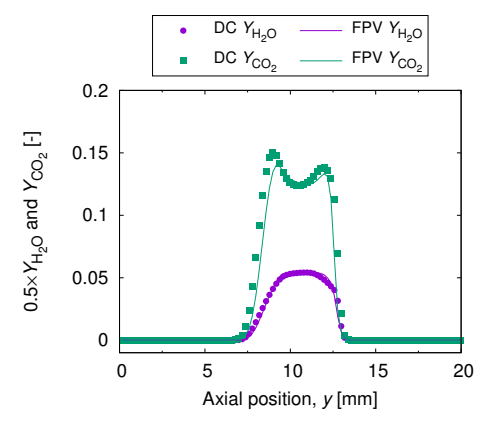

(b) $\mathrm{H}_{2} \mathrm{O}$ and $\mathrm{CO}_{2}$

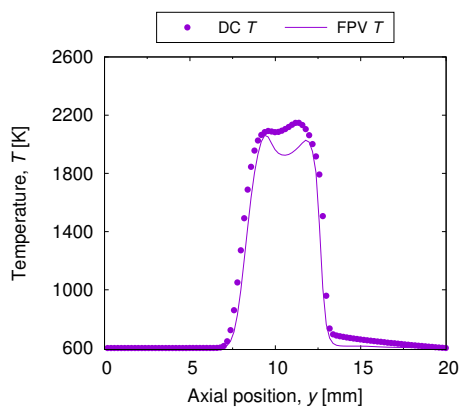

(d) gas temperature

Fig 17. Comparison of the axial profiles of the mass fractions of (a) $\mathrm{CH}_{4}$ and $\mathrm{O}_{2}$, (b) $\mathrm{H}_{2} \mathrm{O}$ and $\mathrm{CO}_{2}$, and (c) $\mathrm{H}_{2}, \mathrm{CO}$ and $\mathrm{OH}$ and (d) the gas temperature between the a posteriori FPV model and detailed chemistry in Case 2 at an elapsed time of $0.05 \mathrm{~s}$. 

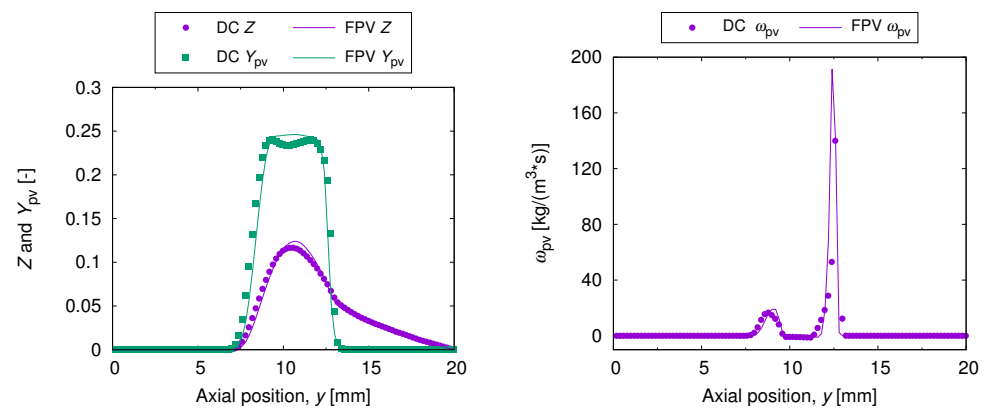

(a) mixture fraction and progress vari- (b) production rate of progress variable able

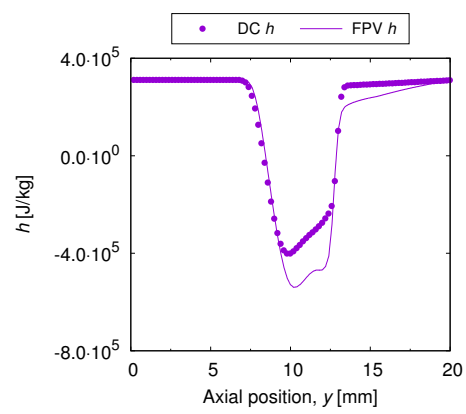

(c) enthalpy

Fig 18. Axial distributions of the (a) mixture fraction and progress variable, (b) production rate of progress variable, and (c) enthalpy calculated using the a posteriori FPV model and detailed chemistry along the center line in Case 2 at an elapsed time of $0.05 \mathrm{~s}$.

Fig. [1] shows scatter plots of the gas temperature as a function of the mixture fraction in Case 2 generated using the a posteriori FPV model. Although the shapes of the scatter plots are almost the same as those obtained using the detailed chemistry during devolatilization (see Fig. سل responds to the branch with $Z_{2}=0$, the last halves move further toward the fuel-rich side. As this shift increases with increasing $Z_{2}$, the departure of these results from the detailed chemistry results should be attributable to excessive char combustion progress in the a posteriori FPV model. In terms of the FI 
during devolatilization and char combustion, positive and negative values, respectively, are observable. Thus, the a posteriori FPV model can describe the combustion modes of both volatile and char off-gas flame. However, the FI also became negative during devolatilization, which was not observed in the scatter plots obtained using the detailed chemistry. To clarify the cause of this behavior, Fig. 20 shows the axial distributions of the mass fractions of fuel and oxidant gas calculated using the a posteriori FPV model and detailed chemistry. Focusing on the ignition points of the volatile gas at $y=12.5 \mathrm{~mm}$, the mass fraction of fuel begins to decrease at the location at which the mass fraction of $\mathrm{O}_{2}$ also begin to decrease, resulting in the positive $F I$ in the detailed chemistry results. On the other hand, in the a posteriori FPV model, the decrease in the mass fraction of fuel is slightly late and the region in which the mass fraction of fuel continues to increase overlaps with the combustion region. In this case, the direction of the fuel gradient is opposite to that of $\mathrm{O}_{2}$ and the FI becomes negative. In summary, excessive devolatilization and char combustion progress caused the results of this model to differ somewhat from those of the detailed chemistry. 


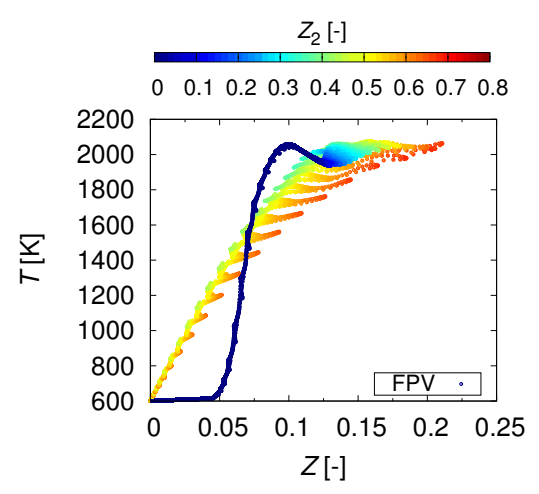

(a) $Z_{2}$

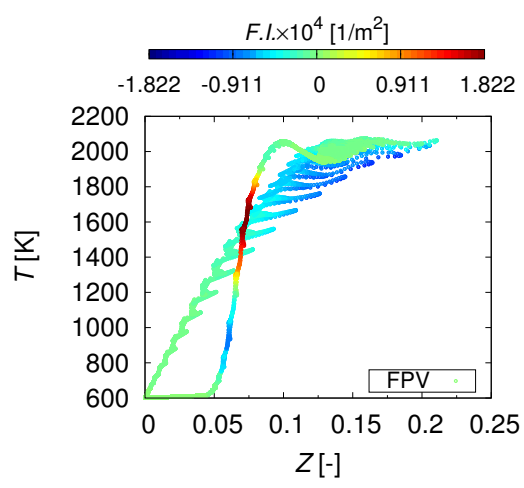

(b) FI

Fig 19. Scatter plots of the gas temperature as a function of the mixture fraction in Case 2 obtained using the a posteriori FPV model and colored according to (a) $Z_{2}$ and (b) FI. The plots were extracted from the steady-state distribution.

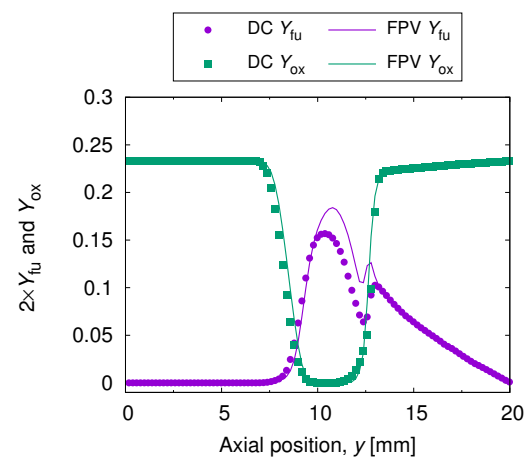

Fig 20. Axial distributions of the mass fractions of fuel and oxidant gas calculated using the a posteriori FPV model and detailed chemistry along the center line in Case 2 at an elapsed time of $0.05 \mathrm{~s}$.

The a posteriori FPV model was also verified in the other cases. Figs. $2 \pi$ and 22 show the distributions of the mass fractions of $\mathrm{CH}_{4}$ and $\mathrm{O}_{2}$ and the 550 gas temperature in Cases 3 and 4, respectively. The a posteriori FPV model reproduced all of the detailed chemistry distributions irrespective of the coal/air 
ratio. However, in Case 3, the a posteriori FPV model struggled to predict the combustion behavior and the accuracy seems to decrease. For example, the volatile matter release rates are less than those in the detailed chemistry results and the increase in the mass fraction of $\mathrm{O}_{2}$ after the combustion process occurs slightly earlier. This earlier end of the chemical reaction influences the gas temperature derived using the a posteriori FPV model, which is lower than that obtained from the detailed chemistry at the lower side of the chemical reaction zone. As shown in Fig. ए2(a), the chemical reactions in Case 3 occur in fuel-rich conditions farther from the stoichiometric mixture, and the progress variable in this study may not be appropriate for describing the progress of chemical reactions. Consequently, the applicability of the FPV model to pulverized coal combustion can be confirmed and the accuracy of the numerical simulations is expected to be improved by implementing the FPV model in CFD simulations for pulverized coal combustion.

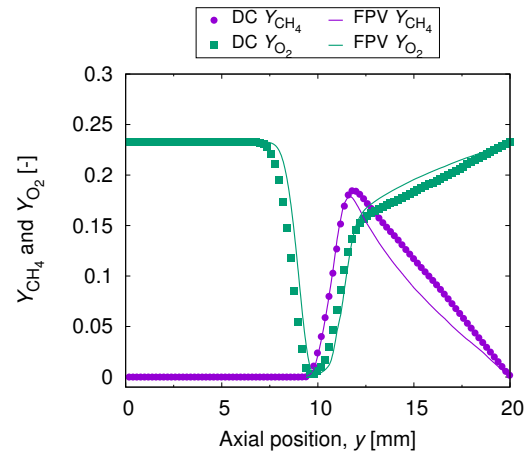

(a) $\mathrm{CH}_{4}$ and $\mathrm{O}_{2}$

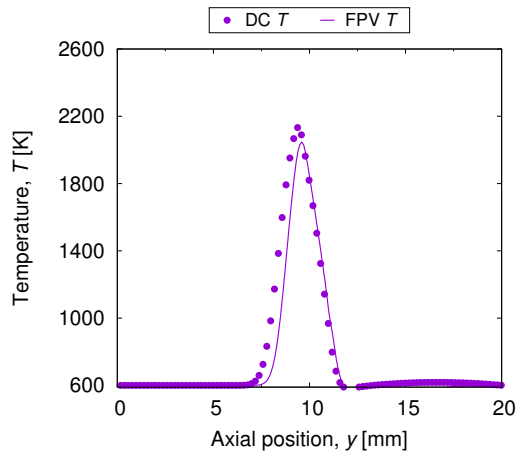

(b) gas temperature

Fig 21. Comparison of the instantaneous profiles of the (a) mass fractions of $\mathrm{CH}_{4}$ and $\mathrm{O}_{2}$ and (b) gas temperature between the a posteriori FPV model and detailed chemistry in Case 3 at an elapsed time of $0.05 \mathrm{~s}$. 


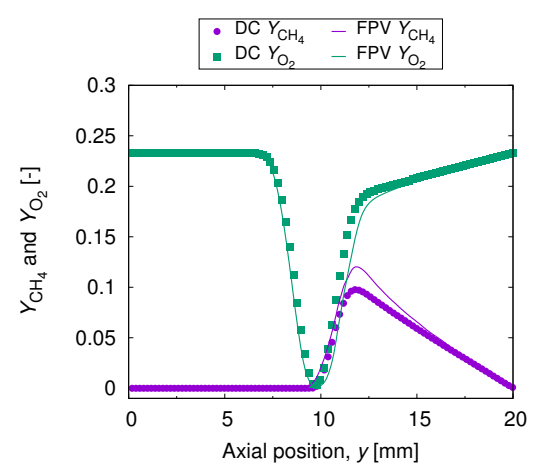

(a) $\mathrm{CH}_{4}$ and $\mathrm{O}_{2}$

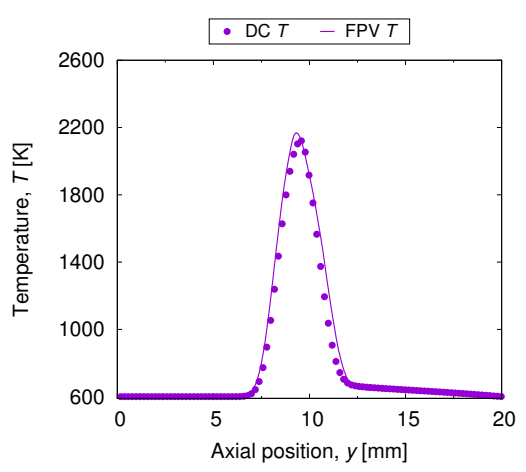

(b) gas temperature

Fig 22. Comparison of the instantaneous profiles of the (a) mass fractions of $\mathrm{CH}_{4}$ and $\mathrm{O}_{2}$ and (b) gas temperature between the a posteriori FPV model and detailed chemistry in Case 4 at an elapsed time of $0.05 \mathrm{~s}$.

\section{Conclusions}

In this study, the structures of the counter-flow diffusion flames of pulverized coals were numerically assessed and the FPV model was validated using the detailed chemistry solution. The look-up tables were constructed based on the two mixture fraction approach described by Rieth et al. [14], and a data set for the additional dimension of enthalpy was prepared by changing the boundary temperature in the one-dimensional calculations. In the present computational domain, a two-stage combustion process was observed, including the combustion of volatile matter and career gas, which showed the premixed combustion mode, and the combustion of unburnt volatile matter and char off-gas, which showed the nonpremixed combustion mode. Interestingly, the premixed region approached the nonpremixed region when the inlet velocity was reduced because of the higher fuel concentration and local quenching by heat transfer between the gas and solid phases. By conducting an a priori test, the validity of the constructed look-up tables was corroborated because the a priori FPV model reproduced the numerical solution obtained using the detailed chemistry. 
Although the a posteriori FPV model also captured the overall trend of the numerical solution in the detailed chemistry, a slight deviation was observed in the ignition process. The decrease in prediction accuracy was expressed by the overpredicted progress variable because nearly all of the thermochemical quantities were retrieved from the look-up table, which was constructed by steady-state flamelet calculation. Consequently, although the present extended FPV model for pulverized coal combustion has room for further improvement to capture the ignition process, the applicability was sufficiently confirmed by the validation tests at various coal/air ratios.

\section{Acknowledgments}

This work was supported by the Japan Society for the Promotion of Science (JSPS) Grant-in-Aid for Research Fellows [grant number 18J11135].

\section{Appendix}

A.1. Effects of the reaction mechanism on the numerical results obtained using detailed chemistry

Fig. A.] shows the instantaneous gas temperature distributions corresponding to different reaction mechanisms. The two temperature distributions are qualitatively similar. To evaluate the difference between the reaction mechanism quantitatively, axial profiles of $\mathrm{CH}_{4}, \mathrm{O}_{2}$, and the gas temperature are displayed in Fig. A.2. There is no significant difference between the two types of reaction mechanisms. Therefore, the knowledge obtained from DRM 22 in this study should be reliable, even though the number of chemical species and reactions included in the detailed chemistry is relatively small compared with that for the other reaction mechanism. 


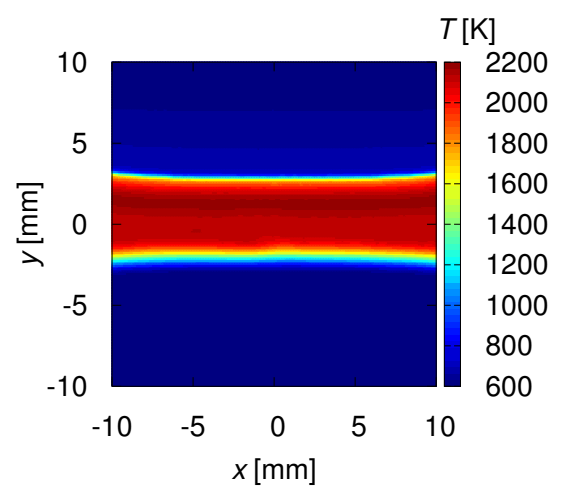

(a) DRM $22[\overline{20}]$

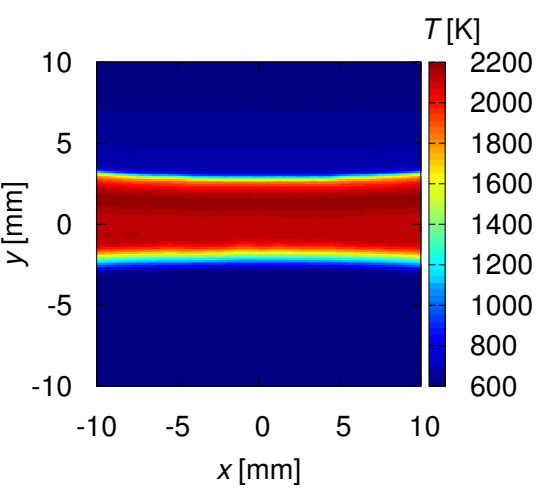

(b) GRI-mech $3.0[\underline{[2 Z}]$

Fig A.1. Instantaneous distributions of the gas temperature with (a) DRM 22 [20] and (b) GRI-mech 3.0 [22] reaction mechanisms at an elapsed time of 0.05 s.

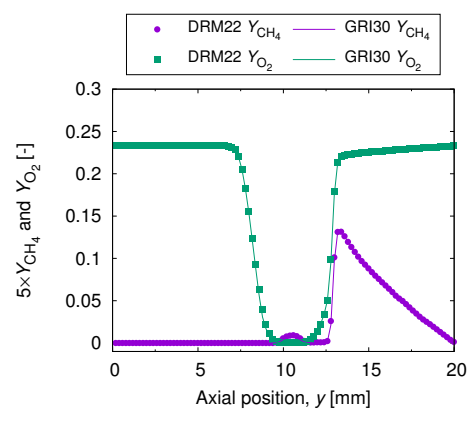

(a) $\mathrm{CH}_{4}$ and $\mathrm{O}_{2}$

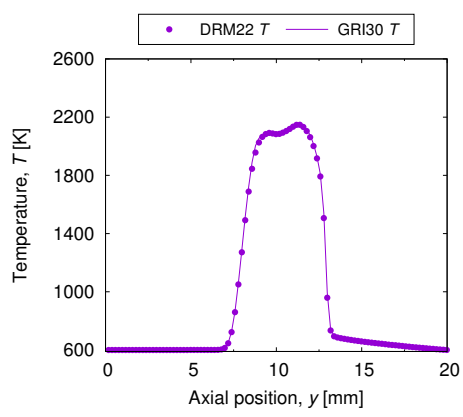

(b) gas temperature

Fig A.2. Axial profiles of (a) major species and (b) gas temperature with different reaction mechanisms at an elapsed time of $0.05 \mathrm{~s}$.

\section{A.2. Effects of the number of computational cells on the numerical results}

Fig. A.3 shows the instantaneous gas temperature distributions with different mesh resolutions. The gas temperature distribution in the domain with $200 \times 200$ cells is almost the same as that in the domain with $300 \times 300$ cells. No 
gas temperature, as shown in Fig. A.4. This finding indicates that the present simulation was performed with a sufficient number of computational cells.

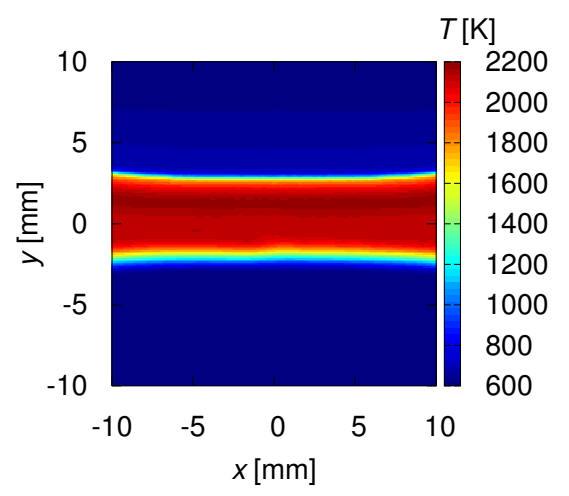

(a) $200 \times 200$

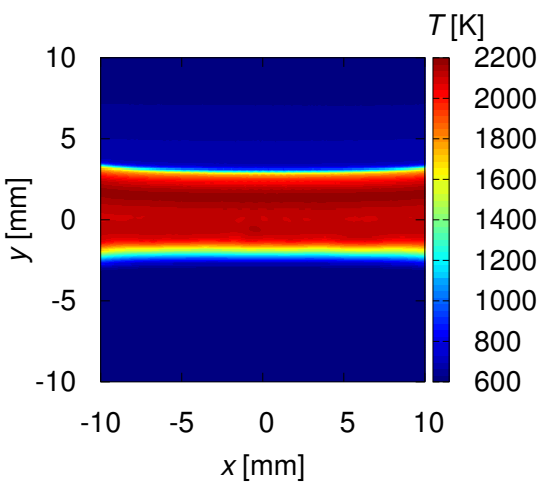

(b) $300 \times 300$

Fig A.3. Instantaneous gas temperature distributions with (a) $200 \times 200$ and (b) $300 \times 300$ cells at an elapsed time of $0.05 \mathrm{~s}$.

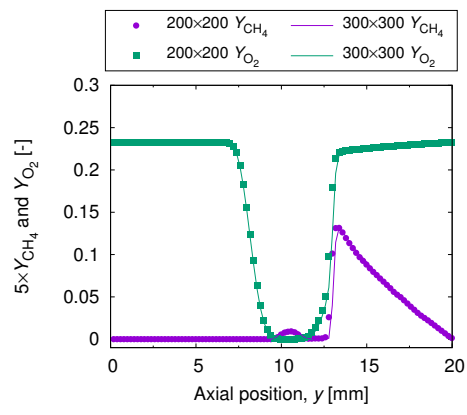

(a) $\mathrm{CH}_{4}$ and $\mathrm{O}_{2}$

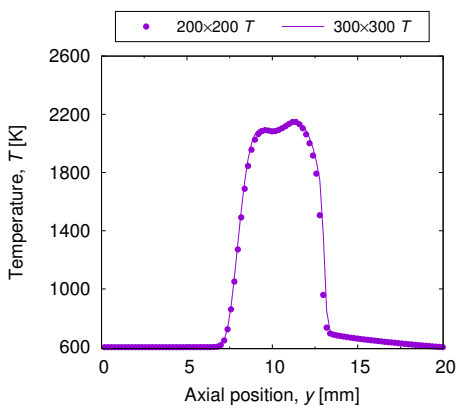

(b) gas temperature

Fig A.4. Axial profiles of (a) major species and (b) gas temperature with different numbers of cells at an elapsed time of $0.05 \mathrm{~s}$.

\section{References}

[1] D. B. Spalding, Mixing and chemical reaction in steady confined turbulent flames, Symposium (International) on Combustion 13 (1971) 649-657. 
[2] B. F. Magnussen, B. H. Hjertager, On mathematical modeling of turbulent combustion with special emphasis on soot formation and combustion, Symposium (International) on Combustion 16 (1977) 719-729.

[3] L. Y. Hu, L. X. Zhou, J. Zhang, Large-eddy simulation of a swirling diffusion flame using a som sgs combustion model, Numerical Heat Transfer, Part B: Fundamentals 50 (2006) 41-58.

[4] P. E. DesJardin, S. H. Frankel, Large eddy simulation of a nonpremixed reacting jet: Application and assessment of subgrid-scale combustion models, Physics of Fluids 10 (1998) 2298-2314.

[5] R. Kurose, H. Makino, A. Suzuki, Numerical analysis of pulverized coal combustion characteristics using advanced low-nox burner, Fuel 83 (2004) 693-703.

[6] B. M. Franchetti, F. Cavallo Marincola, S. Navarro-Martinez, A. M. Kempf, Large eddy simulation of a pulverised coal jet flame, Proceedings of the Combustion Institute 34 (2013) 2419-2426.

[7] M. Rabaçal, B. M. Franchetti, F. C. Marincola, F. Proch, M. Costa, C. Hasse, A. M. Kempf, Large eddy simulation of coal combustion in a large-scale laboratory furnace, Proceedings of the Combustion Institute 35 (2015) 3609-3617.

[8] M. Muto, Prediction of nox formation in pulverized coal combustion fields using large-eddy simulation - application to multi-scale combustion fields -, Journal of the Society of Powder Technology, Japan 52 (2015) 658-662.

[9] S. Ahn, K. Tanno, H. Watanabe, Numerical analysis of particle dispersion and combustion characteristics on a piloted coaxial pulverized coal jet ${ }_{640} \quad$ flame, Applied Thermal Engineering 124 (2017) 1194-1202.

[10] M. Vascellari, H. Xu, C. Hasse, Flamelet modeling of coal particle ignition, Proceedings of the Combustion Institute 34 (2013) 2445-2452. 
[11] J. Watanabe, K. Yamamoto, Flamelet model for pulverized coal combustion, Proceedings of the Combustion Institute 35 (2015) 2315-2322.

[12] A. Molina, C. R. Shaddix, Ignition and devolatilization of pulverized bituminous coal particles during oxygen/carbon dioxide coal combustion, Proceedings of the Combustion Institute 31 (2007) 1905-1912.

[13] X. Wen, K. Luo, Y. Luo, H. I. Kassem, H. Jin, J. Fan, Large eddy simulation of a semi-industrial scale coal furnace using non-adiabatic three-stream flamelet/progress variable model, Applied Energy 183 (2016) 1086-1097.

[14] M. Rieth, F. Proch, M. Rabaçal, B. M. Franchetti, F. Cavallo Marincola, A. M. Kempf, Flamelet les of a semi-industrial pulverized coal furnace, Combustion and Flame 173 (2016) 39-56.

[15] M. Rieth, F. Proch, A. G. Clements, M. Rabaçal, A. M. Kempf, Highly resolved flamelet les of a semi-industrial scale coal furnace, Proceedings of the Combustion Institute 36 (2017) 3371-3379.

[16] X. Wen, K. Luo, H. Jin, J. Fan, Large eddy simulation of piloted pulverised coal combustion using extended flamelet/progress variable model, Combustion Theory and Modelling 21 (2017) 925-953.

[17] H. Pitsch, A c++ program package for 0d combustion and 1d laminar flame calculations, available at http://www.itv.rwth-aachen.de/index.php? id $=128$ (accessed on July 22, 2019).

[18] C. Hasse, N. Peters, A two mixture fraction flamelet model applied to split injections in a di diesel engine, Proceedings of the Combustion Institute 30 (2005) 2755-2762.

[19] C. Felsch, M. Gauding, C. Hasse, S. Vogel, N. Peters, An extended flamelet model for multiple injections in di diesel engines, Proceedings of the Combustion Institute 32 (2009) 2775-2783. 
[20] A. Kazakov, M. Frenklach, Reduced reaction sets based on gri-mech 1.2, available at http://combustion.berkeley.edu/drm/ (accessed on July $22,2019)$.

[21] X. Wen, H. Wang, Y. Luo, K. Luo, J. Fan, Numerical investigation of the effects of volatile matter composition and chemical reaction mechanism on pulverized coal combustion characteristics, Fuel 210 (2017) 695-704.

[22] G. P. Smith, D. M. Golden, M. Frenklac, N. W. Moriarty, B. Eiteneer, M. Goldenberg, C. T. Bowman, R. K. Hanson, S. Song, W. C. Gardiner Jr., V. V. Lissianski, Z. Qin, Gri-mech 3.0, available at http://combustion. berkeley.edu/gri-mech (accessed on July 22, 2019).

[23] X. Wen, H. Wang, Y. Luo, K. Luo, J. Fan, Evaluation of flamelet/progress variable model for laminar pulverized coal combustion, Physics of Fluids 29 (2017) 083607.

[24] B. Marracino, D. Lentini, Radiation modelling in non-luminous nonpremixed turbulent flames, Combustion Science and Technology 128 (1997) $23-48$.

[25] M. Hossain, J. Jones, W. Malalasekera, Modelling of a bluff-body nonpremixed flame using a coupled radiation/flamelet combustion model, Flow, Turbulence and Combustion 67 (2001) 217-234.

[26] A. Kishimoto, H. Moriai, K. Takenaka, T. Nishiie, M. Adachi, A. Ogawara, R. Kurose, Application of a nonadiabatic flamelet/progress-variable approach to large-eddy simulation of h2/o2 combustion under a pressurized condition, Journal of Heat Transfer 139 (2017) 124501-124501-4. 10.1115/1.4037099.

[27] F. Proch, A. M. Kempf, Modeling heat loss effects in the large eddy simulation of a model gas turbine combustor with premixed flamelet generated manifolds, Proceedings of the Combustion Institute 35 (2015) 3337-3345. 
[28] K. Luo, C. Zhao, X. Wen, Z. Gao, Y. Bai, J. Xing, J. Fan, A priori study of an extended flamelet/progress variable model for no prediction in pulverized coal flames, Energy 175 (2019) 768-780.

[29] X. Wen, Y. Luo, H. Wang, K. Luo, H. Jin, J. Fan, A three mixture fraction flamelet model for multi-stream laminar pulverized coal combustion, Proceedings of the Combustion Institute 37 (2019) 2901-2910.

[30] S.-M. Hwang, R. Kurose, F. Akamatsu, H. Tsuji, H. Makino, M. Katsuki, Application of optical diagnostics techniques to a laboratory-scale turbulent pulverized coal flame, Energy \& Fuels 19 (2005) 382-392.

[31] S.-M. Hwang, R. Kurose, F. Akamatsu, H. Tsuji, H. Makino, M. Katsuki, Observation of detailed structure of turbulent pulverized-coal flame by optical measurement (part 1, time-averaged measurement of behavior of pulverized-coal particles and flame structure), JSME International Journal Series B Fluids and Thermal Engineering 49 (2006) 1316-1327.

[32] W. P. Jones, S. Lyra, S. Navarro-Martinez, Large eddy simulation of a swirl stabilized spray flame, Proceedings of the Combustion Institute 33 (2011) 2153-2160.

[33] R. Clift, J. R. Grace, M. E. Weber, Bubbles, drops, and particles, Academic Press, New York, 1978.

[34] D. Merrick, Mathematical models of the thermal decomposition of coal: 2. specific heats and heats of reaction, Fuel 62 (1983) 540-546.

[35] B. S. Brewster, L. L. Baxter, L. D. Smoot, Treatment of coal devolatilization in comprehensive combustion modeling, Energy \& Fuels 2 (1988) 362-370.

${ }_{720}$ [36] M. Stöllinger, B. Naud, D. Roekaerts, N. Beishuizen, S. Heinz, Pdf modeling and simulations of pulverized coal combustion - part 2: Application, Combustion and Flame 160 (2013) 396-410. 
[37] X. Wen, K. Luo, H. Wang, Y. Luo, J. Fan, Analysis of pulverized coal flame stabilized in a 3d laminar counterflow, Combustion and Flame 189 (2018) 106-125.

[38] W. Ranz, W. Marshall, Evaporation from drops: Part i, Chemical Engineering Progress 48 (1952) 141-146.

[39] S. Akaotsu, J. Tanimoto, T. Soma, Y. Saito, Y. Matsushita, H. Aoki, A. Murao, Development of semi-parallel reaction model of devolatilization and heterogeneous reaction for pulverized coal particles, Fuel Processing Technology 158 (2017) 104-114.

[40] S. Badzioch, P. G. W. Hawksley, Kinetics of thermal decomposition of pulverized coal particles, Industrial \& Engineering Chemistry Process Design and Development 9 (1970) 521-530.

735 [41] O. T. Stein, G. Olenik, A. Kronenburg, F. Cavallo Marincola, B. M. Franchetti, A. M. Kempf, M. Ghiani, M. Vascellari, C. Hasse, Towards comprehensive coal combustion modelling for les, Flow, Turbulence and Combustion 90 (2013) 859-884.

[42] T. Hara, M. Muto, T. Kitano, R. Kurose, S. Komori, Direct numerical simulation of a pulverized coal jet flame employing a global volatile matter reaction scheme based on detailed reaction mechanism, Combustion and Flame 162 (2015) 4391-4407.

[43] X.-Y. Zhao, D. C. Haworth, Transported pdf modeling of pulverized coal jet flames, Combustion and Flame 161 (2014) 1866-1882.

745 [44] M. M. Baum, P. J. Street, Predicting the combustion behaviour of coal particles, Combustion Science and Technology 3 (1971) 231-243.

[45] J. Arthur, Reactions between carbon and oxygen, Transactions of the Faraday Society 47 (1951) 164-178. 
[46] L. Tognotti, J. P. Longwell, A. F. Sarofim, The products of the high temperature oxidation of a single char particle in an electrodynamic balance, Symposium (International) on Combustion 23 (1991) 1207-1213.

[47] C. R. Shaddix, F. Holzleithner, M. Geier, B. S. Haynes, Numerical assessment of tognotti determination of co2/co production ratio during char oxidation, Combustion and Flame 160 (2013) 1827-1834.

[48] M. A. Field, Rate of combustion of size-graded fractions of char from a low-rank coal between $1200 \mathrm{k}$ and $2000 \mathrm{k}$, Combustion and Flame 13 (1969) 237-252.

[49] C. T. Crowe, M. P. Sharma, D. E. Stock, The particle-source-in cell (psicell) model for gas-droplet flows, Journal of Fluids Engineering 99 (1977) 325-332. 10.1115/1.3448756.

[50] S.-C. S. Ou, K.-N. Liou, Generalization of the spherical harmonic method to radiative transfer in multi-dimensional space, Journal of Quantitative Spectroscopy and Radiative Transfer 28 (1982) 271-288.

[51] P. Cheng, Two-dimensional radiating gas flow by a moment method, AIAA Journal 2 (1964) 1662-1664.

[52] Y. Matsushita, S. Akaotsu, S. Yokoi, Y. Saito, H. Aoki, An approximate method for the computation of wall temperature using thermal equilibrium and fluid temperatures from the enthalpy and mole fraction, JOURNAL OF CHEMICAL ENGINEERING OF JAPAN 50 (2017) 111-114.

[53] S. Yokoi, Y. Matsukawa, Y. Saito, Y. Matsushita, H. Aoki, W. Malalasekera, A modified boundary condition of velocity for continuity equation with non-uniform density distribution at outlet boundary plane, JOURNAL OF CHEMICAL ENGINEERING OF JAPAN 51 (2018) 641-645.

[54] P. L. Roe, Characteristic-based schemes for the euler equations, Annual Review of Fluid Mechanics 18 (1986) 337-365. 
[55] S. V. Patankar, D. B. Spalding, A calculation procedure for heat, mass and momentum transfer in three-dimensional parabolic flows, International Journal of Heat and Mass Transfer 15 (1972) 1787-1806.

[56] N. Nomura, A. Fujii, T. Tanaka, O. Marques, K. Nakajima, Algebraic multigrid solver using coarse grid aggregation with independent aggregation, IEEE International Parallel and Distributed Processing Symposium Workshops (IPDPSW) (2018).

[57] H. A. v. d. Vorst, Bi-cgstab: A fast and smoothly converging variant of bi-cg for the solution of nonsymmetric linear systems, SIAM Journal on Scientific and Statistical Computing 13 (1992) 631-644.

[58] P. N. Brown, G. D. Byrne, A. C. Hindmarsh, Vode: A variable-coefficient ode solver, SIAM Journal on Scientific and Statistical Computing 10 (1989) $1038-1051$.

[59] A. A. Amsden, F. H. Harlow, A simplified mac technique for incompressible fluid flow calculations, Journal of Computational Physics 6 (1970) 322-325.

[60] H. Yamashita, M. Shimada, T. Takeno, A numerical study on flame stability at the transition point of jet diffusion flames, Symposium (International) on Combustion 26 (1996) 27-34.

[61] M. Rieth, A. M. Kempf, O. T. Stein, A. Kronenburg, C. Hasse, M. Vascellari, Evaluation of a flamelet/progress variable approach for pulverized coal combustion in a turbulent mixing layer, Proceedings of the Combustion Institute 37 (2019) 2927-2934. 